\title{
The Solubilities and Thermodynamic Equilibrium of Anhydrite and Gypsum
}

\author{
K. Serafeimidis · G. Anagnostou
}

Received: 2 May 2013/ Accepted: 9 February 2014/Published online: 25 February 2014

(C) Springer-Verlag Wien 2014

\begin{abstract}
Anhydritic claystones consist of a clay matrix with finely distributed anhydrite. Their swelling has led to severe damage and high repair costs in several tunnels. Gypsum growth combined with water uptake by the clay minerals is the main cause of the swelling process. Identifying the conditions under which gypsum rather than anhydrite represents the stable phase is crucial for understanding rock swelling. As existing studies on the anhydrite-gypsum-water equilibrium appear to be contradictory and do not provide all of the information required, we revisit this classic problem here by formulating and studying a thermodynamic model. In contrast to earlier research, our model is not limited to the anhydrite-gypsum equilibrium, but allows for the determination of the equilibrium concentrations of the individual anhydrite dissolution and gypsum precipitation reactions that underlie the sulphate transformation. The results of the paper are, therefore, also valuable for the formulation of comprehensive sulphate-water interaction models that consider diffusive and advective ion transport simultaneously with the chemical dissolution and precipitation reactions. Furthermore, in addition to the influencing factors that have been considered by previous studies (i.e., fluid and solid pressures, concentration of foreign ions, temperature), we consistently incorporate the effect of the surface energy of the sulphate crystals into the thermodynamic equations and discuss the effect of the clay minerals on the equilibrium conditions. The surface energy effects, which are important particularly in the case of claystones with extremely small pores, increase the solubility of gypsum, thus shifting the thermodynamic equilibrium in favour of anhydrite. Clay
\end{abstract}

K. Serafeimidis · G. Anagnostou ( $\square)$

ETH, Zurich, Switzerland

e-mail: georg.anagnostou@igt.baug.ethz.ch minerals also favour anhydrite because they lower the activity of the water. The predictions from the model are compared with experimental results and with predictions from other models in the literature. Finally, a comprehensive equilibrium diagram is presented in terms of pore water pressure, solid pressure, temperature, water activity and pore size.

Keywords Anhydrite - Gypsum · Equilibrium · Solubility · Swelling · Gypsum Keuper

\section{List of Symbols}

A Parameter of Davies equation

$A_{i} \quad$ Total interfacial area of species $i$

C Concentration

$c_{0} \quad$ Concentration at standard state

$c_{\text {eq,A }} \quad$ Anhydrite equilibrium concentration

$c_{\mathrm{eq}, \mathrm{G}} \quad$ Gypsum equilibrium concentration

$c_{i} \quad$ Concentration of constituent $i$

$g \quad$ Gravitational acceleration

$G \quad$ Gibbs free energy

I Ionic strength

$K_{\mathrm{G}} \quad$ Ion activity product of gypsum

$K_{\text {eq,A }}$ Equilibrium solubility product of anhydrite

$K_{\text {eq,G }} \quad$ Equilibrium solubility product of gypsum

$n_{\mathrm{Ca}^{2+}} \quad$ Number of moles of $\mathrm{Ca}^{2+}$

$n_{\mathrm{G}} \quad$ Number of moles of gypsum

$n_{\mathrm{W}} \quad$ Number of moles of water

$n_{i} \quad$ Number of moles of constituent $i$

$n_{\mathrm{SO}_{4}^{2-}} \quad$ Number of moles of $\mathrm{SO}_{4}^{2-}$

$p_{\text {A }} \quad$ Anhydrite pressure

$P_{\text {atm }} \quad$ Atmospheric pressure

$p_{\mathrm{G}} \quad$ Gypsum pressure

$P_{i} \quad$ Pressure of constituent $i$

$p_{\mathrm{S}} \quad$ Solid pressure 
$p_{\mathrm{V}} \quad$ Vapour pressure of a solution

$p_{\mathrm{V}, 0} \quad$ Vapour pressure of pure water

$p_{\mathrm{W}} \quad$ Pore water pressure

$Q \quad$ Heat

$R \quad$ Universal gas constant

$r_{\mathrm{p}} \quad$ Pore radius

$r_{i} \quad$ Radius of particle $i$

$r_{\mathrm{A}} \quad$ Radius of anhydrite particles

$r_{\mathrm{G}} \quad$ Radius of gypsum particles

$S_{\mathrm{Ca}^{2+}}^{0} \quad$ Molar entropy of $\mathrm{Ca}^{2+}$ at standard state

$S_{\mathrm{A}}^{0} \quad$ Molar entropy of anhydrite at standard state

$S_{\mathrm{G}}^{0} \quad$ Molar entropy of gypsum at standard state

$S_{\mathrm{W}}^{0} \quad$ Molar entropy of water at standard state

$S_{i} \quad$ Molar entropy of constituent $i$

$S_{i} \quad$ Molar entropy of constituent $i$ at standard state

$S_{\mathrm{SO}_{4}^{2-}}^{0} \quad$ Molar entropy of $\mathrm{SO}_{4}^{2-}$ at standard state

$T$ Temperature

$T_{0} \quad$ Temperature at standard state

$T_{\text {eq }} \quad$ Equilibrium temperature

$T_{\mathrm{eq}}^{0} \quad$ Equilibrium temperature under atmospheric pressure

$U \quad$ Internal energy

$V \quad$ Volume

$V_{\mathrm{Ca}^{2+}}^{0} \quad$ Molar volume of $\mathrm{Ca}^{2+}$ at standard state

$V_{\mathrm{A}}^{0} \quad$ Molar volume of anhydrite at standard state

$V_{\mathrm{G}}^{0} \quad$ Molar volume of gypsum at standard state

$V_{\mathrm{W}}^{0} \quad$ Molar volume of water at standard state

$V_{i} \quad$ Molar volume of constituent $i$

$V_{\mathrm{W}} \quad$ Molar volume of water

$V_{i}^{0} \quad$ Molar volume of constituent $i$ at standard state

$V_{\mathrm{SO}_{4}^{2-}}^{0} \quad$ Molar volume of $\mathrm{SO}_{4}^{2-}$ at standard state

$H \quad$ Depth below surface

$z_{i} \quad$ Ion valence of constituent $i$

\section{Greek Symbols}

$\alpha_{\mathrm{Ca}^{2+}} \quad$ Activity of $\mathrm{Ca}^{2+}$

$\alpha_{\mathrm{G}} \quad$ Activity of gypsum

$\alpha_{\mathrm{W}} \quad$ Water activity

$\alpha_{i} \quad$ Activity of constituent $i$

$\alpha_{\mathrm{SO}_{4}^{2-}} \quad$ Activity of $\mathrm{SO}_{4}^{2-}$

$\gamma_{ \pm} \quad$ Mean activity coefficient

$\gamma_{\mathrm{A}} \quad$ Surface free energy of the anhydrite-water interface

$\gamma_{\mathrm{Ca}^{2+}} \quad$ Activity coefficient of $\mathrm{Ca}^{2+}$

$\gamma_{\mathrm{G}} \quad$ Surface free energy of the gypsum-water interface

$\gamma_{i} \quad$ Surface free energy of the interface of constituent $i$ with water

$\gamma_{i} \quad$ Activity coefficient of constituent $i$

$\gamma_{\mathrm{SO}_{4}^{2-}} \quad$ Activity coefficient of $\mathrm{SO}_{4}^{2-}$

$\Delta_{\mathrm{f}} G_{\mathrm{Ca}^{2+}}^{0+} \quad$ Standard Gibbs energy of formation of $\mathrm{Ca}^{2+}$
$\Delta_{\mathrm{f}} G_{\mathrm{A}}^{0} \quad$ Standard Gibbs energy of formation of anhydrite

$\Delta_{\mathrm{f}} G_{\mathrm{G}}^{0} \quad$ Standard Gibbs energy of formation of gypsum

$\Delta_{\mathrm{f}} G_{\mathrm{W}}^{0} \quad$ Standard Gibbs energy of formation of water

$\Delta_{\mathrm{f}} G_{i}^{0} \quad$ Standard Gibbs energy of formation of constituent $i$

$\Delta_{\mathrm{f}} G_{\mathrm{SO}_{4-}^{2-}}^{0} \quad$ Standard Gibbs energy of formation of $\mathrm{SO}_{4}^{2-}$

$\Delta_{\mathrm{r}, \mathrm{A}} G^{0} \quad$ Standard Gibbs energy of anhydrite dissolution

$\Delta_{\mathrm{r}, \mathrm{G}} G^{0} \quad$ Standard Gibbs energy of gypsum dissolution

$\Delta_{\mathrm{r}, \mathrm{GA}} G^{0} \quad$ Standard Gibbs energy of anhydrite hydration

$\Delta_{\mathrm{r}, \mathrm{A}} S^{0} \quad$ Standard entropy of anhydrite dissolution

$\Delta_{\mathrm{r}, \mathrm{G}} S^{0} \quad$ Standard entropy of gypsum dissolution

$\Delta_{\mathrm{r}, \mathrm{GA}} S^{0} \quad$ Standard entropy of anhydrite hydration

$\Delta_{\mathrm{r}, \mathrm{A}} V^{0} \quad$ Standard volume of anhydrite dissolution

$\Delta_{\mathrm{r}, \mathrm{G}} V^{0} \quad$ Standard volume of gypsum dissolution

$\Delta_{\mathrm{r}, \mathrm{GA}} V^{0} \quad$ Standard volume of anhydrite hydration

$\varepsilon \quad$ Dielectric constant (Davies equation)

$\lambda_{\mathrm{W}} \quad$ Ater activity coefficient

$\mu_{\mathrm{Ca}^{2+}} \quad$ Chemical potential of formation of $\mathrm{Ca}^{2+}$

$\mu_{\mathrm{A}} \quad$ Chemical potential of formation of anhydrite

$\mu_{\mathrm{G}} \quad$ Chemical potential of formation of gypsum

$\mu_{\mathrm{W}} \quad$ Chemical potential of formation of water

$\mu_{i} \quad$ Chemical potential of constituent $i$

$\mu_{\mathrm{SO}_{4}^{2-}} \quad$ Chemical potential of formation of $\mathrm{SO}_{4}^{2-}$

$\rho_{\mathrm{R}} \quad$ Rock density

$\rho_{\mathrm{W}} \quad$ Water density

$x_{\mathrm{W}} \quad$ Mole fraction of water

$\Psi \quad$ Potential

$\Psi_{\mathrm{m}} \quad$ Matric potential

$\Psi_{\pi} \quad$ Osmotic potential

$\Psi_{\mathrm{a}} \quad$ Adsorptive component of the matric potential

$\Psi_{\mathrm{c}} \quad$ Capillary component of the matric potential

\section{Introduction}

The distinguishing feature of swelling rocks is that they increase their volume when they come into contact with water. In tunnelling, the swelling manifests itself as a heave of the tunnel floor or-in the presence of a lining-as pressure upon the lining. Anhydritic claystones, i.e. rocks consisting of a clay matrix with finely distributed anhydrite, are particularly problematic in this respect. They are encountered frequently in North-Western Switzerland and South-Western Germany (Gypsum Keuper formation) and have caused serious damage and operational problems in numerous tunnels, with high repair costs (Amstad and Kovári 2001). Anagnostou et al. (2010) discussed the mechanisms underlying swelling qualitatively and identified a series of fundamental questions which are essential for understanding this phenomenon. The swelling of anhydritic rocks is attributed to the transformation of 
anhydrite into gypsum crystals. This transformation takes place via the solution phase, i.e. via anhydrite dissolution and gypsum precipitation. The chemical dissolution and precipitation reactions of gypsum and anhydrite are

$\mathrm{CaSO}_{4} \cdot 2 \mathrm{H}_{2} \mathrm{O} \leftrightarrow \mathrm{Ca}^{2+}+\mathrm{SO}_{4}^{2-}+2 \mathrm{H}_{2} \mathrm{O}$

and

$\mathrm{CaSO}_{4} \leftrightarrow \mathrm{Ca}^{2+}+\mathrm{SO}_{4}^{2-}$,

respectively.

In a system where different minerals co-exist, the mineral with the lower solubility (equilibrium concentration) represents the stable phase. The transformation thus takes place as a result of the solubility of the anhydrite being higher than that of gypsum under the conditions normally prevailing in tunnelling through the Gypsum Keuper formation (rather low temperatures and pressures, see end of the current Section). More specifically, anhydrite in contact with water starts to dissolve into calcium and sulphate ions until the ionic concentration in the pore solution reaches the equilibrium concentration of anhydrite. Before this happens, however, the concentration reaches the solubility of gypsum with the consequence that gypsum starts to precipitate, thus consuming ions and maintaining a state of undersaturation with respect to anhydrite until the all of the anhydrite is dissolved.

Van't Hoff et al. (1903) were the first ones to investigate the conditions under which anhydrite and gypsum occur in salt deposits. Since then, the system $\mathrm{CaSO}_{4}-\mathrm{H}_{2} \mathrm{O}$ (with or without other salts) has been examined by several authors both experimentally and theoretically, based on the thermodynamic concept of Gibbs Free Energy. An extended review of the literature on the $\mathrm{CaSO}_{4}-\mathrm{H}_{2} \mathrm{O}$ system can be found in Freyer and Voigt (2003). Nonetheless, most of the studies are outdated, and many are semi-empirical and fail to provide all the necessary information, while their results often appear to be contradictory (cf. review by Freyer and Voigt 2003). For instance, the gypsum-anhydrite transition temperature remains ambiguous to this day. The proposed values are between $38^{\circ} \mathrm{C}$ (Toriumi and Hara 1938) and $63.5^{\circ} \mathrm{C}$ (Van't Hoff et al. 1903). Furthermore, Freyer and Voigt (2003) showed by means of thermodynamic calculations that the transition temperature (for saturated $\mathrm{NaCl}$ solution) varies considerably depending on which thermodynamic data from the literature are used. The determination of the transition temperature is difficult probably due to the fact that at temperatures below $70{ }^{\circ} \mathrm{C}$ anhydrite does not crystallise in water with measurable rates, even in the presence of anhydrite seeds (Freyer and Voigt 2003).

The following passages summarise the most relevant work in this area. Posnjak (1938), Bock (1961), Zen (1965), Hardie (1967) and Innorta et al. (1980) investigated the role of temperature and salts in the gypsum and anhydrite solubilities at atmospheric pressure experimentally. The salt which has been focused on in most studies is $\mathrm{NaCl}$, as it is the most prominent foreign pore water constituent in evaporite deposits (MacDonald 1953). Blount and Dickson (1973) performed experiments to estimate anhydrite and gypsum solubilities in aqueous and $\mathrm{NaCl}$ solutions at different temperatures and pressures up to 1,000 bars. Based on their own experimental results and on experimental data found in the literature, they proposed empirical equations for the determination of anhydrite and gypsum solubilities. Nevertheless, according to Blount and Dickson (1973), the empirical equation proposed for the equilibrium concentration of anhydrite does not provide reliable results at temperatures below $70{ }^{\circ} \mathrm{C}$, as the results had to be extrapolated in this region.

Marsal (1952) studied the influence of the water pressure on the system $\mathrm{CaSO}_{4}-\mathrm{H}_{2} \mathrm{O}$ thermodynamically, treating the hydration of anhydrite into gypsum as a topochemical reaction. Furthermore, he defined the temperature and pressure conditions under which anhydrite or gypsum is the stable phase. MacDonald (1953) investigated the role of temperature, pressure and dissolved $\mathrm{NaCl}$ on the transition point based also on the thermodynamics of a topochemical reaction. He treated the different pressures acting on the solid and liquid phases (lithostatic and hydrostatic pressure, respectively) in an innovative way and investigated which mineral is stable in pure water and $\mathrm{NaCl}$ solutions at different depths below the surface. Rolnick (1954) confirmed experimentally the theoretical predictions of MacDonald (1953) and extended their range towards extremely high pressures (up to 2,000 bar which corresponds to an overburden of approximately $8.5 \mathrm{~km}$ ). Similar investigations with $\mathrm{NaCl}$-saturated solutions have been performed by Hanshaw and Bredehoeft (1968). Raju and Atkinson (1990) developed a thermodynamic model for the separate prediction of anhydrite and gypsum solubilities in water and aqueous $\mathrm{NaCl}$ solutions at atmospheric pressure and up to a temperature of 250 and $110{ }^{\circ} \mathrm{C}$ for anhydrite and gypsum, respectively. Kontrec et al. (2002) performed experiments to study the kinetics of anhydrite dissolution and gypsum dissolution and precipitation at temperatures between 10 and $40{ }^{\circ} \mathrm{C}$. Moreover, they proposed a mathematical model for the evolution of the transformation processes.

Despite the above-mentioned disagreements regarding the transition temperature, the following qualitative conclusions are generally accepted: (1) an increase in pressure increases the solubilities of anhydrite and gypsum to different extents; (2) the presence of salts such as $\mathrm{NaCl}$ in the solution both increases the solubilities and lowers the temperature at which anhydrite and gypsum coexist; and (3), the equilibrium concentration of anhydrite decreases with increasing temperature, while the equilibrium concentration of gypsum changes only slightly with temperature. 
The existing theoretical models for the anhydrite-gypsum equilibrium take account of the temperature, of the solid and liquid pressures and of the effect of foreign ions in the solution. In the case of small pores, however, the crystal size is an additional important factor (Steiger 2005b; Scherer 1999; Flatt and Scherer 2008). More specifically, according to the Ostwald-Freundlich equation (also known as Gibbs-Thomson and Kelvin equation), the equilibrium concentration increases with decreasing crystal size (Freundlich 1922). Another effect, which should be considered in the case of claystones with finely distributed anhydrite, is that clay minerals lower the chemical potential of the water, thus increasing the solubility of gypsum and shifting the thermodynamic equilibrium in favour of anhydrite. The present paper incorporates these effects in the thermodynamic equations consistently and discusses the effects of clay minerals on water activity (Sects. 2.3.3, 2.4).

Furthermore, almost all theoretical studies deal with the equilibrium between anhydrite and gypsum without investigating the anhydrite-water and the gypsum-water equilibria, i.e. without presenting theoretical estimations of the anhydrite and gypsum solubilities. An exception to this is the work of Raju and Atkinson (1990), which, however, refers only to sulphate dissolution/precipitation under atmospheric conditions. The intermediate stage can in fact be disregarded when investigating the anhydrite-gypsum equilibrium, i.e. it is sufficient to consider one single reaction for the anhydrite-gypsum transformation $\left(\mathrm{CaSO}_{4}+2 \mathrm{H}_{2} \mathrm{O} \leftrightarrow \mathrm{CaSO}_{4} \cdot 2 \mathrm{H}_{2} \mathrm{O}\right)$, because both phases exhibit the same solubility at equilibrium and are in equilibrium with the pore solution. However, in contrast to existing studies, we approach the thermodynamic equilibrium problem starting from the two individual dissolution/ precipitation reactions (Eqs. 1,2) and the determination of equilibrium concentrations of anhydrite and gypsum (Sect. 3 ). The results of the paper thus extend our recent study on the kinetics of sulphate dissolution and precipitation reactions (Serafeimidis and Anagnostou 2012, 2013) and are also valuable as a component of future comprehensive claystone-sulphate-water interaction models addressing diffusive and advective transport (seepage flow) simultaneously with chemical dissolution and precipitation reactions.

The paper is organised as follows: starting with an overview of the fundamental thermodynamic principles (Sect. 2), we derive mathematical relationships for the gypsum and anhydrite solubilities (Sect. 3) and formulate the gypsum-anhydrite equilibrium condition in terms of temperature, pore water pressure, pressure in the solid phase and crystal size (Sect. 4). Sections 5 and 6 compare the predicted solubilities and equilibrium conditions, respectively, with existing experimental data and third-
Table 1 Depth of tunnels in Gypsum Keuper

\begin{tabular}{lcc}
\hline Tunnel & $\begin{array}{l}\text { Minimum } \\
\text { overburden } \\
\text { in Gypsum } \\
\text { Keuper (m) }\end{array}$ & $\begin{array}{l}\text { Maximum } \\
\text { overburden } \\
\text { in Gypsum } \\
\text { Keuper (m) }\end{array}$ \\
\hline Wagenburg Tunnel $^{\mathrm{a}}$ & 40 & 50 \\
Schanz Tunnel $^{\mathrm{b}}$ & 20 & 90 \\
Kappelesberg Tunnel $^{\mathrm{c}}$ & 30 & 80 \\
Hauenstein Base-Tunnel $^{\mathrm{d}}$ & 270 & 300 \\
Belchen Tunnel $^{\mathrm{e}}$ & 45 & 370 \\
Chienberg Tunnel $^{\mathrm{f}}$ & 20 & 120 \\
Engelberg Base-Tunnel $^{\mathrm{g}}$ & 40 & 85 \\
Freudenstein Tunnel $^{\mathrm{h}}$ & 50 & 100 \\
Adler Tunnel $^{\mathrm{i}}$ & 10 & 110 \\
Bözberg Tunnel $^{\mathrm{j}}$ & 75 & 100 \\
Mont Terri $^{\mathrm{k}}$ & 115 & 360 \\
Lilla Tunnel $^{\mathrm{l}}$ & 20 & 115 \\
\hline
\end{tabular}

$\overline{\text { a }}$ Paul and Wichter (1996), ${ }^{\mathrm{b}}$ Schaechterle (1929), ${ }^{\mathrm{c}}$ Kurz and Spang (1984), ${ }^{\mathrm{d}}$ Einstein (2000), ${ }^{\mathrm{e}}$ Grob (1972), ${ }^{\mathrm{f}}$ Butsher et al. (2011), ${ }^{\mathrm{g}}$ Beck and Thullner (1998), ${ }^{\mathrm{h}}$ Kirschke et al. (1991), ${ }^{\mathrm{i}}$ Meyer (2001),

${ }^{\mathrm{j}}$ Hauber (1991), ${ }^{\mathrm{k}}$ Schaeren and Norbert (1989), ${ }^{1}$ Berdugo (2007)

party computations for pure water and $\mathrm{NaCl}$ solutions. Finally, Sect. 7 presents and discusses an equilibrium diagram, which covers a wide range of the parameters that govern the gypsum-anhydrite equilibrium.

In all derivations the sign convention of geomechanics will be adopted, according to which compressive stresses are positive. Furthermore, although the equations are given in a general form, attention will be paid to the parameter range, which corresponds to the pressure, temperature and salinity conditions prevailing in tunnelling through the Gypsum Keuper formation. Tunnels (Table 1) cross this formation at depths between $10 \mathrm{~m}$ (Adler Tunnel) and $370 \mathrm{~m}$ (Belchen Tunnel). Taking into account a unit weight for the rock and the water of 24 and $10 \mathrm{kN} / \mathrm{m}^{3}$, respectively, the overburden pressure and the pore water pressure are equal to a maximum of 9 and $3.7 \mathrm{MPa}$, respectively. Furthermore, considering the geothermal gradient in Switzerland (30-40 ${ }^{\circ} \mathrm{C} / \mathrm{km}$, Medici and Rybach 1995), the temperature $T$ is in the range of $15-30{ }^{\circ} \mathrm{C}$. With regard to salinity, we will make use of chemical analysis data from three Swiss tunnels crossing the Gypsum Keuper formation (Table 2).

\section{Basic Thermodynamic Relations}

\subsection{Gibbs Free Energy}

We start with the fundamental thermodynamic relationships governing the anhydrite-gypsum-water system. For 
Table 2 Ion concentrations and maximum ionic strength for three Swiss tunnels in Gypsum Keuper

\begin{tabular}{llll}
\hline $\begin{array}{l}\text { Ion concentration } \\
(\mathrm{mmol} / \mathrm{l})\end{array}$ & $\begin{array}{l}\text { Belchen } \\
\text { Tunnel }^{\mathrm{a}}\end{array}$ & $\begin{array}{l}\text { Chienberg } \\
\text { Tunnel }^{\mathrm{b}}\end{array}$ & $\begin{array}{l}\text { Adler } \\
\text { Tunnel }^{\mathrm{c}}\end{array}$ \\
\hline${\text { Calcium } \mathrm{Ca}^{2+}}^{2-}$ & $0.18-19$ & $0.78-21$ & $1.7-15$ \\
${\text { Sulphate } \mathrm{SO}_{4}{ }^{2-}}^{\text {Sodium } \mathrm{Na}^{+}}$ & $0.14-96$ & $0.29-36$ & $0.4-19.4$ \\
${\mathrm{Chloride} \mathrm{Cl}^{-}}^{\text {Potassium } \mathrm{K}^{+}}$ & $2.7-137$ & $<25.6$ & $0.23-6.5$ \\
Hydroxide $\mathrm{OH}^{-}$ & $0.11-186$ & $<2.5$ & $<5.5$ \\
Carbonate $\mathrm{CO}_{3}{ }^{-}$ & $0.6-13$ & & \\
Magnesium $\mathrm{Mg}^{2+}$ & $2.3-29$ & & \\
Max. ionic strength I (mmol/l) & 429 & 152 & 89 \\
\hline
\end{tabular}

${ }^{a}$ Wegmüller (2001), Huggenberger (2012), Noher and Meyer (2002)

b LPM (2000-6), Lothenbach (2012)

c Zehringer (1997), Bachema (1995-1997)

further details on thermodynamics within a geological context, the reader is referred to textbooks, e.g. Anderson (1996) and White (2005). According to the first law of thermodynamics, assuming for simplicity that the product of pressure and volume change is the only mechanical work done by the system, the internal energy differential can be written as

$\mathrm{d} U=\mathrm{d} Q-\sum_{i} P_{i} n_{i} \mathrm{~d} V_{i}+\sum_{i} \mu_{i} \mathrm{~d} n_{i}$,

where $\mathrm{d} Q$ denotes the energy supplied to the system as heat. The subscript $i$ denotes the $i$ th constituent of the system. In the present case $i=\mathrm{Ca}^{2+}, \mathrm{SO}_{4}{ }^{2-}, \mathrm{H}_{2} \mathrm{O}, \mathrm{CaSO}_{4}$ and $\mathrm{CaSO}_{4} \cdot 2 \mathrm{H}_{2} \mathrm{O}$. (For the sake of brevity, the subscripts W, A and $\mathrm{G}$ will be used instead of the chemical formulae of water, anhydrite and gypsum, respectively.) The second term on the right-hand side of Eq. (3) denotes the mechanical work performed when $n_{i}$ moles of the systemconstituent $i$ experience the molar volume change $\mathrm{d} V_{i}$ while being subject to the pressure $P_{i}$. As in previous research into the $\mathrm{CaSO}_{4}-\mathrm{H}_{2} \mathrm{O}$ system (see references in Sect. 1), we remain within the framework of hydrostatic thermodynamics. Mechanical work is, therefore, expressed in Eq. (3) in terms of volume changes and pressures (mean stresses). The pressure $P_{i}$ in Eq. (3) is equal to $p_{\mathrm{w}}+P_{\mathrm{atm}}$ for the water and the ions, and to $p_{\mathrm{s}}+P_{\mathrm{atm}}$ for the solid phase, where $p_{\mathrm{w}}, p_{\mathrm{s}}$ and $P_{\mathrm{atm}}$ denote the pore water pressure, the macroscopic solid pressure (Dahlen 1992) and the atmospheric pressure, respectively. (As is usual in geomechanics, the stresses are taken in excess of the atmospheric pressure, i.e. a stress of zero means that the medium is actually under atmospheric pressure.) The macroscopic solid pressure $p_{\mathrm{s}}$ represents the average pressure experienced by the grains (Dewers and Ortoleva 1989) and will be referred hereafter simply as "solid pressure".
The last term of Eq. (3) represents the change in internal energy due to chemical reactions, i.e. due to the changes in the molar quantities $n_{i}$. The symbol $\mu_{i}$ denotes the molar chemical potential of constituent $i$ and depends in general on the temperature $T$ and on the pressure $P_{i}$ (see Sect. 2.2).

According to the second law of thermodynamics,

$T \sum_{i} n_{i} \mathrm{~d} S_{i} \geq \mathrm{d} Q$,

where the equality sign applies to reversible processes while $T$ and $S_{i}$ denote the temperature and the molar entropy of constituent $i$, respectively.

The Gibbs free energy

$G=U+\sum_{i} P_{i} n_{i} V_{i}-T \sum_{i} n_{i} S_{i}$

or after integrating Eq. (3) at constant values of the intensive properties,

$G=\sum_{i} n_{i} \mu_{i}$

For a reversible process we obtain from Eqs. (3), (4) and (5) the Gibbs Free Energy increment:

$\mathrm{d} G=\sum \mu_{i} \mathrm{~d} n_{i}+\sum n_{i} V_{i} \mathrm{~d} P_{i}-\sum n_{i} S_{i} \mathrm{~d} T$.

According to this equation, the chemical potential $\mu_{i}$ of the substance $i$ is equal to the change in the Gibbs Free Energy $G$ due to the formation of $1 \mathrm{~mol}$ of this substance under constant temperature and pressure. The direction of a chemical reaction depends on the difference in the Gibbs Free Energy $G$ between the products and the reactants: Any transformation in a system takes place to minimise $G$, i.e. a chemical reaction will occur spontaneously from a state of high Gibbs Free Energy $G$ to a state of low $G$. In a system at equilibrium, the Gibbs Free Energies $G$ of the products and of the reactants are equal.

\subsection{Chemical Potential}

The molar chemical potential $\mu_{i}$ at arbitrary temperature $T$ and pressure $P_{i}$ can be expressed as a function of $T$, of $P_{i}$ and of the chemical potential $\left.\mu_{i}\right|_{T_{0}, P_{\text {atm }}}$ at standard temperature $T_{0}\left(298.15 \mathrm{~K}\right.$ or $\left.25^{\circ} \mathrm{C}\right)$ and atmospheric pressure $P_{\mathrm{atm}}$. In order to do that, we consider a system consisting of one substance only. In the absence of chemical reactions, we obtain from Eqs. (6) and (7)

$\mathrm{d} \mu_{i}=\mathrm{d} G=V_{i} \mathrm{~d} P_{i}-S_{i} \mathrm{~d} T$.

For a constant molar volume $V_{i}$ and entropy $S_{i}$, which is a reasonable simplification for the constituents of the gypsum-anhydrite-water system (without gases), the integration of Eq. (8) leads to 
Table 3 Standard Gibbs energies of formation, molar volumes and entropies (after Anderson 1996, with the exception of $V_{\mathrm{SO}_{4}^{2-}}^{0}$, which is after Millero 1972)

\begin{tabular}{lccc}
\hline$i$ & $\begin{array}{l}\Delta_{\mathrm{f}} G_{i}^{0} \\
(\mathrm{~kJ} / \mathrm{mol})\end{array}$ & \multicolumn{1}{c}{$\begin{array}{l}V_{i}^{0} \\
\left(\mathrm{~cm}^{3} / \mathrm{mol}\right)\end{array}$} & \multicolumn{1}{c}{$\begin{array}{l}S_{i}^{0} \\
(\mathrm{~J} / \mathrm{mol} / \mathrm{K})\end{array}$} \\
\hline $\mathrm{CaSO}_{4}$ & $-1,321.79$ & 45.94 & 106.70 \\
$\mathrm{CaSO}_{4} \cdot 2 \mathrm{H}_{2} \mathrm{O}$ & $-1,797.28$ & 74.30 & 194.10 \\
$\mathrm{H}_{2} \mathrm{O}$ & -237.12 & 18.00 & 69.91 \\
$\mathrm{Ca}^{2+}$ & -553.58 & -18.40 & -53.10 \\
$\mathrm{SO}_{4}^{2-}$ & -744.53 & 13.98 & 20.10 \\
\hline
\end{tabular}

$\mu_{i}=\left.\mu_{i}\right|_{T_{0}, P_{\text {atm }}}+V_{i}\left(P_{i}-P_{\text {atm }}\right)-S_{i}\left(T-T_{0}\right)$.

Under certain conditions, which will be detailed below, the chemical potential $\left.\mu_{i}\right|_{T_{0}, P_{\text {atm }}}$ of the species $i$ at atmospheric pressure and standard temperature is identical to its standard Gibbs energy of formation, $\Delta_{\mathrm{f}} G_{i}^{0}$, which can be found in thermodynamic tables (see Table 3 for the constituents of the gypsum-anhydrite-water system). The conditions mentioned are that (1) the water and the dissolved ions are in their standard states, and (2) liquidcrystal interfacial effects can be neglected for the solid species. In general, the chemical potential can be written as

$\left.\mu_{i}\right|_{T_{0}, P_{\text {atm }}}=\Delta_{\mathrm{f}} G_{i}^{0}+R T \ln a_{i}+\gamma_{i} \frac{\mathrm{d} A_{i}}{\mathrm{~d} n_{i}}$,

where $R, a_{i}, \gamma_{i}$, and $A_{i}$ denote the universal gas constant ( $R=8.31 \mathrm{~J} / \mathrm{K} / \mathrm{mol}$ ), the activity of the species $i$, the surface free energy of the crystal-water interface and the total interfacial area of the species $i$, respectively. The second and the third term on the right-hand side account for deviations from conditions (1) and (2), respectively and will be explained in detail in Sects. 2.3 and 2.4. Inserting $\left.\mu_{i}\right|_{T_{0}, P_{\text {atm }}}$ from Eq. (10) into Eq. (9) leads to the following general expression for the chemical potential of species $i$ :

$\begin{aligned} \mu_{i}= & \Delta_{\mathrm{f}} G_{i}^{0}+R T \ln a_{i}+\gamma_{i} \frac{\mathrm{d} A_{i}}{\mathrm{~d} n_{i}}+V_{i}\left(P_{i}-P_{\mathrm{atm}}\right) \\ & -S_{i}\left(T-T_{0}\right),\end{aligned}$

where the second term on the right-hand side is non-zero only for the water and the ions, while the third term is nonzero only for the solid species.

\subsection{Activity}

\subsubsection{General}

At standard state, the activity $a_{i}$ is by definition equal to 1 and the second term in Eq. (11) disappears. Standard state with respect to a specific ion (in addition to the conditions of atmospheric pressure and $25{ }^{\circ} \mathrm{C}$ temperature) means that its concentration amounts to $c_{0}=1 \mathrm{~mol} / \mathrm{l}$ and that there are no other ions in the solution. Water is in its standard state only if it is pure (or almost pure, i.e. a very dilute solution). High ionic concentrations or the presence of clay minerals decrease the water and ion activities and thus also their chemical potentials. Details about the activities $a_{i}$ of water and ions are given in Sects. 2.3.2, 2.3.3 and 2.3.4, respectively. The standard state of the solid species is characterised solely by the conditions of atmospheric pressure and a temperature of $25^{\circ} \mathrm{C}$ and, consequently, the activity of solids is equal to 1 . Therefore, the second term on the right-hand side of Eq. (11) disappears for the anhydrite and gypsum crystals.

\subsubsection{Activity of Water in the Presence of Ions}

As mentioned above, the activity of pure water is equal to one. In the presence of ions, the water activity

$a_{\mathrm{W}}=x_{\mathrm{W}} \lambda_{\mathrm{W}}$,

where $x_{\mathrm{W}}$ is the mole fraction of the water, defined as the amount of a water $n_{\mathrm{W}}$ divided by the total amount of all the system constituents, i.e.

$x_{\mathrm{W}}=\frac{n_{\mathrm{W}}}{\sum_{i} n_{i}}$,

and $\lambda_{\mathrm{W}}$ is the water activity coefficient. The latter accounts for the interactions among the ions in the solution and is in general $\leq 1$. For very dilute solutions, both $\lambda_{\mathrm{W}}$ and $\chi_{\mathrm{w}}$ and thus also $a_{\mathrm{W}}$ equal unity. The water activity coefficient $\lambda_{\mathrm{W}}$ can be determined using, e.g., the Pitzer (1973) or the Davies (1962) equations. Due to the limitations of the theoretical models, the experimental methods applied are frequently based on the following relationship between the activity and the water vapour pressure $p_{\mathrm{V}}$ on the solution (Blandamer et al. 2005):

$a_{\mathrm{W}}=\frac{p_{\mathrm{V}}}{p_{\mathrm{V}, 0}}$,

where $p_{\mathrm{V}, 0}$ is the vapour pressure of pure water at the same temperature. Data concerning the decrease in the vapour pressure in salt solutions as a function of the temperature and concentration can be found in the literature. For example, according to Washburn (1926-1933), $a_{\mathrm{W}}=0.75$ for a saturated $\mathrm{NaCl}$ solution $\left(c \approx 6 \mathrm{~mol} / \mathrm{l}, x_{\mathrm{W}} \approx 0.89\right)$ at $T=30^{\circ} \mathrm{C}$.

\subsubsection{Effect of Clay Minerals on Water Activity}

The pore water in a clayey material generally has an activity less than unity. The underlying causes on the micro-scale are the increased ionic concentration in the vicinity of the clay platelets and the intermolecular forces acting between the clay surface and the water. In general, 
water activity can be calculated using the Kelvin equation (cf. Scanlon et al. 2002):

$a_{\mathrm{W}}=\exp \left(\frac{\Psi V_{\mathrm{W}}}{R T}\right)$

where $\Psi<0$ is the potential of the soil-water, $T$ the temperature in $\mathrm{K}, R$ the gas constant and $V_{\mathrm{W}}$ the molar volume of water.

The potential $\Psi$ can be defined as 'the work done on a unit mass of water, required to move it from a free water surface to a point in the soil' (Yong and Warkentin 1975), and it consists in its very general form of several components (Yong 1999). Nonetheless, the selection of components is not standardised and appears to be rather arbitrary in the literature. In the current study, the following general expression is considered (Passioura 1980; Yong 1999):

$\Psi=\Psi_{\pi}+\Psi_{\mathrm{m}}$

where $\Psi_{\pi}$ and $\Psi_{\mathrm{m}}$ denote the osmotic and the matric potential, respectively. (The expression given by Passioura (1980), and Yong (1999), includes the pressure potential as an additional term. This term was omitted here from Eq. (16) because the pore water pressure was dealt with in Eq. (11).) The two components of the water potential according to Eq. (16) are discussed in the following paragraphs.

The osmotic potential $\Psi_{\pi}$ is associated with the ionic concentration in the soil water. The clay minerals carry negative electric charges. The pore water between the clay platelets is actually a salt solution in which the cations balance these negative electric charges (Dormieux et al. 2003). The clay platelets thus have a similar function to that of a semipermeable membrane in a normal osmotic system, i.e. they restrain the ions (Atkins and De Paula 2006).

As the potential of the pore water is lower than that of the free water far away from the clay minerals, water flows towards the inter-platelet space and pushes the clay platelets apart. The swelling of the clay can thus be attributed to the activity difference between the free water and the pore water. The osmotic potential can either be calculated theoretically by considering the clay platelets on the microscale (Madsen and Müller-Vonmoos 1988) or determined experimentally (cf. Fermi 1936). Note that strains also occur in clayey rock due to changes in the osmotic potential, i.e. the latter is "effective" in the sense of the soil mechanics principle of effective stress. Osmotic swelling occurs at water activities $>0.9$, while at low water activities (unsaturated systems) intracrystalline swelling takes place (Bihannic et al. 2009; Mering 1946). The latter is associated with the hydration of the interlamellar spaces, which results in an increase in the crystal distance.

The matric potential $\Psi_{\mathrm{m}}$ is made up of two components, the adsorptive component $\Psi_{\mathrm{a}}$ and the capillary component $\Psi_{\mathrm{c}}$ (Philip 1977; Tuller et al. 1999). In general, when a liquid comes in contact with a solid, a thin liquid film forms around the solid surface and surface forces (suction forces) develop (Chenevert 1969; Derjaguin et al. 1987). More specifically, the interfacial interactions between the clay surface and the water result in a decrease in the chemical potential of water in the adsorbed film. This decrease induces a further gradient between the chemical potentials of the water of the film and the water in the bulk, which in turn causes an additional water flow in the system and thus also swelling (Mitchell and Soga 2005). The adsorptive component $\Psi_{\mathrm{a}}$ depends on the thickness of the adsorbed water layer. According to Low and Margheim (1979), who provided a relationship for the swelling pressure of clays, the thinner the adsorbed water layer (i.e. the less water), the higher is the swelling pressure.

The capillary component $\Psi_{\mathrm{c}}$ applies to partly saturated porous media and results from the stresses transmitted to the water phase from pressures developed by concave menisci at the water-vapour interfaces, causing a decrease in the pore water pressure (Passioura 1980, Mitchell and Soga 2005). $\Psi_{\mathrm{c}}$ depends on the mean curvature of the water-vapour interphase and is given by the YoungLaplace equation (cf. Tuller et al. 1999).

Nevertheless, as verified by crystalline swelling tests, differences in the water content might result in gradients of matric potential and thus in water movement, even for the case of saturated systems. Therefore, the term 'capillary flow' is used in the literature (Derjaguin et al. 1987). It is common for clays to exhibit high suction values even under saturated conditions where capillary flow may take place due to suction differences (Yong and Warkentin 1975).

It is not possible to measure the two components ( $\Psi_{\text {a }}$ and $\Psi_{\mathrm{c}}$ ) of the matric potential separately (Yong and Warkentin 1975). Nonetheless, there are techniques both in the laboratory and in the field for the measurement of the matric potential $\Psi_{\mathrm{m}}$ and the total potential $\Psi$ of water. An extended overview of different measuring methods can be found in Scanlon et al. (2002).

\subsubsection{Activity of Ions}

The activity of an ion $i$ is given by

$a_{i}=\gamma_{i} c_{i} / c_{0}$,

where $c_{i}$ and $\gamma_{i}$ denote its concentration and activity coefficient, respectively, while $c_{0}$ is the concentration at standard state $\left(c_{0}=1 \mathrm{~mol} / \mathrm{l}\right)$. In a similar way to the water activity coefficient, the ion activity coefficient accounts for the interactions among the ions present in the solution. It depends on all ionic concentrations (including foreign ions) and is generally $\leq 1$. For an extremely dilute solution, $\gamma_{i}$ equals unity, i.e. the activity $\alpha_{i}$ of the constituent $i$ is equal to its concentration $c_{i}$ in $\mathrm{mol} / \mathrm{l}$. 
Activity coefficients can be measured experimentally only for salts, and not for single ions. Nonetheless, several theoretical approaches to the determination of $\gamma_{i}$ have been proposed in the literature (cf., e.g. Merkel and PlanerFriedrich 2008 for a general overview). For dilute solutions, the most common equations are the extended equations of Debye and Hückel (1923) and the equations of Davies (1962), while for highly saline waters the equations of Pitzer (1973) should be applied.

As explained later in this Section, salinities are rather low in the Gypsum Keuper formation. Therefore, the activity coefficients $\gamma_{i}$ will be calculated here according to the Davies equations:

$\log _{10} \gamma_{i}=-A \cdot z_{i}^{2} \cdot\left(\frac{\sqrt{I / c_{0}}}{1+\sqrt{I / c_{0}}}-0.3 I / c_{0}\right)$,

where $z_{i}$ is the valence of the ions $\left(z_{i}=2\right.$ for calcium and sulphate ions) and $I$ is the ionic strength:

$I=0.5 \sum c_{i} z_{i}^{2}$

The coefficient $A$ depends on the temperature:

$A=\frac{1.82483 \cdot 10^{6} \cdot \sqrt{\rho_{\mathrm{W}}}}{(\varepsilon \cdot T)^{3 / 2}}$,

where $T, \rho_{\mathrm{W}}$ and $\varepsilon$ denote the temperature in Kelvin, the water density (in $\mathrm{g} / \mathrm{cm}^{3}$ ) and the dielectric constant (dimensionless). For temperatures up to $80^{\circ} \mathrm{C}$, Gildseth et al. (1972) and Nordstrom et al. (1990) give the following expressions for the water density and for the dielectric constant, respectively,

$\rho_{\mathrm{W}}=1-\frac{(T-277.14)^{2} \cdot(T+15.79)}{508929.2 \cdot(T-205.02)}+0.011445$

and

$\varepsilon=2727.586+0.6224107 \cdot T-466.9151 \cdot \ln T$

$-\frac{52000.87}{T}$

For the usual temperatures in Gypsum Keuper tunnels (15-30 ${ }^{\circ} \mathrm{C}$, cf. Sect. 1), the coefficient $A$ amounts to $0.50-0.52$. Figure 1 shows the activity as a function of the concentration and was calculated based on Eqs. (18), (17), (18), (19), (20), (21), (22) for solutions containing only calcium and sulphate ions with $c_{\mathrm{Ca}^{2+}}=c_{\mathrm{SO}_{4}^{2-}}=c$.

The Davies equations used above give proper results only if the ionic strength $I<500 \mathrm{mmol} / \mathrm{l}$, which, as explained below, is true for the Gypsum Keuper formation. Chemical analyses of water from a number of Swiss tunnels crossing this formation indicate high values for sulphate content and variable values for other ions such as sodium or chloride. For

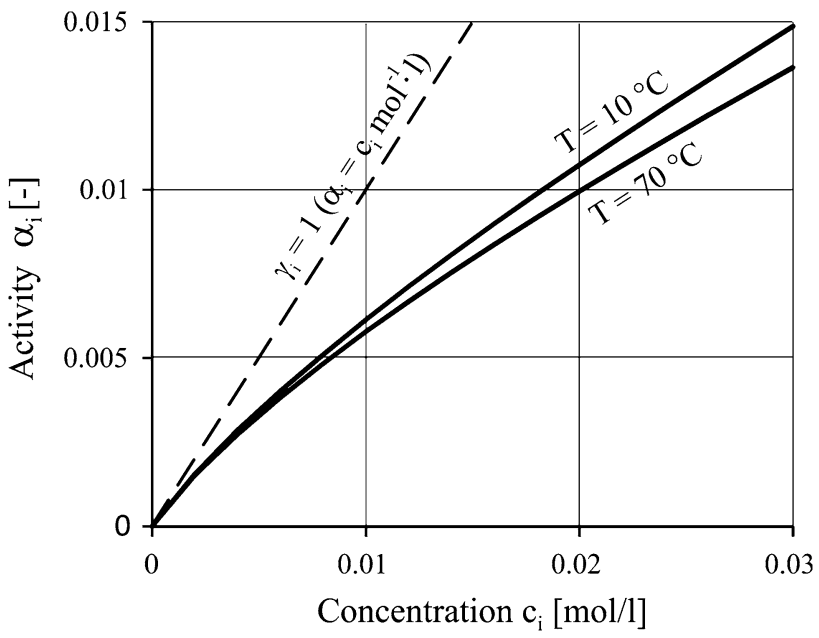

Fig. 1 Activity of solutions containing only calcium and sulphate ions with $c_{\mathrm{Ca}^{2+}}=c_{\mathrm{SO}_{4}^{2-}}=c$ as a function of the concentration $c$ according to the Davies equations

instance, water analyses from different sections of the Belchen Tunnel showed the existence of sodium, calcium, potassium, carbonate, sulphate, hydroxide and chloride ions (Table 2) as well as negligible quantities of magnesium, nitrite $\left(\mathrm{NO}_{2}^{-}\right)$, nitrate $\left(\mathrm{NO}_{3}^{-}\right)$and phosphate $\left(\mathrm{PO}_{4}^{3-}\right)$ ions (not included in Table 2). The investigations on water from the Chienberg Tunnel and the Adler Tunnel revealed the existence of $\mathrm{Ca}^{2+}, \mathrm{SO}_{4}^{2-}, \mathrm{Na}^{+}, \mathrm{Cl}^{-}$and in some cases also magnesium ions as shown in Table 2. In the Adler Tunnel bromide $\left(\mathrm{Br}^{-}\right)$, fluoride $\left(\mathrm{F}^{-}\right)$, nitrate and nitrite ions were additionally detected, though in extremely low concentrations (not included in Table 2). Even if uncertainties exist as to whether the analysed water is identical to the water in the pores or even to the natural groundwater (the composition of which may have altered due to reactions with injection materials and concrete), the high values for sulphate content are characteristic of water from the Gypsum Keuper formation (Noher and Meyer 2002) and agree with the results of chemical analyses of the pore water of Keuper marls (Pearson et al. 2003; Gimmi and Waber 2004).

The last row of Table 2 shows the ionic strength $I$, calculated when considering simultaneously the maximum values of the given concentration ranges (and omitting the very low concentration ions mentioned above). Even in this extreme case, however, the ionic strength $I$ is $<500 \mathrm{mmol} /$ 1, thus justifying the use of the Davies equations. Low ionic strength values were determined also for Keuper marls from the Mont Terri Rock Laboratory and from the Benken borehole of NAGRA (50-180 mmol/1 according to Pearson et al. 2003 and Gimmi and Waber 2004).

A further conclusion that can be drawn from Table 2 is that the sodium and chloride concentrations are rather low. Relatively low concentrations were observed also in the 
pore water of Keuper marls from Mont Terri and Benken ( $<120 \mathrm{mmol} / \mathrm{l}$ sodium and $<15 \mathrm{mmol} / \mathrm{l}$ chloride; Pearson et al. 2003; Gimmi and Waber 2004). Higher sodium and chloride concentrations (up to 300 and $350 \mathrm{mmol} / \mathrm{l}$, respectively, Pearson et al. 2003) were measured in water squeezed out from the pores of Opalinus clay samples from Mont Terri. (Opalinus clay is a slightly younger, Jurassic marine claystone overlying the Keuper marls.) However, even this higher salinity results in ionic strengths of $<400 \mathrm{mmol} / \mathrm{l}$ (Pearson et al. 2003). Opalinus clay specimens from Benken exhibit even lower ionic strengths (94-310 mmol/l; Voegelin and Kretzschmar 2002; Van Loon and Soler 2003).

\subsection{Crystal-Liquid Interfacial Effect}

Solid-liquid interfacial effects increase the chemical potential of the crystals. This is taken into account by the third term on the right-hand side of Eq. (11). This term applies only to the solid species (anhydrite and gypsum crystals in the present case) and corresponds to Eq. (7) of Steiger (2005a). Since $\mathrm{d} A_{i} / \mathrm{d} n_{i}$ is directly related to the specific surface of the crystals, this term can be neglected for large crystals or plane interfaces, but is important for crystals with small curvature radii. Under the simplifying assumptions of spherical particles with radius $r_{i}$ and isotropic surface free energy $\gamma_{i}$, the third term of Eq. (11) is equal to $V_{i} 2 \gamma_{i} / r_{i}$ (cf. Steiger 2005b), which means (as can be confirmed by inspecting Eq. (9)) that the effect of surface energy is equivalent to that of the pressure $P_{i}$ : The surface can be conceived as a stretched membrane that encloses the crystal and exerts a confining pressure of $2 \gamma_{i} / r_{i}$ upon it. Figure 2 shows this apparent confining pressure $2 \gamma_{i} / r_{i}$ as a function of the particle radius $r_{i}$ for the typical range of the interfacial tension $\gamma_{i}$ (which is $10-150 \mathrm{mN} / \mathrm{m}$ according to Nielsen and Söhnel 1971). The apparent confining pressure reaches very high values (several MPa) at small radii, decreases with increasing radius and becomes negligible for radii greater than $1 \mu \mathrm{m}$.

Anhydrite appears in natural rocks either in the form of particles or of layers of different thicknesses and spacings (Serafeimidis and Anagnostou 2012b). The form of the particles may be closer to a sphere, or a rather prismatic form, while their size lies within a wide range, amounting from few $\mu \mathrm{m}$ to few $\mathrm{cm}$. Therefore, the solid-liquid interfacial effects are practically negligible for anhydrite.

However, such effects may be important during gypsum growth inside the pores of anhydritic claystones, since the size of the pores in the rock sets an upper limit on the size of the growing gypsum crystals. According to the literature, both the porosity and the pore size of claystones may be extremely low, while the surface free energy $\gamma_{\mathrm{G}}$ between gypsum and water is in the range $10-120 \mathrm{mN} / \mathrm{m}$ (Tables 4,5 ).

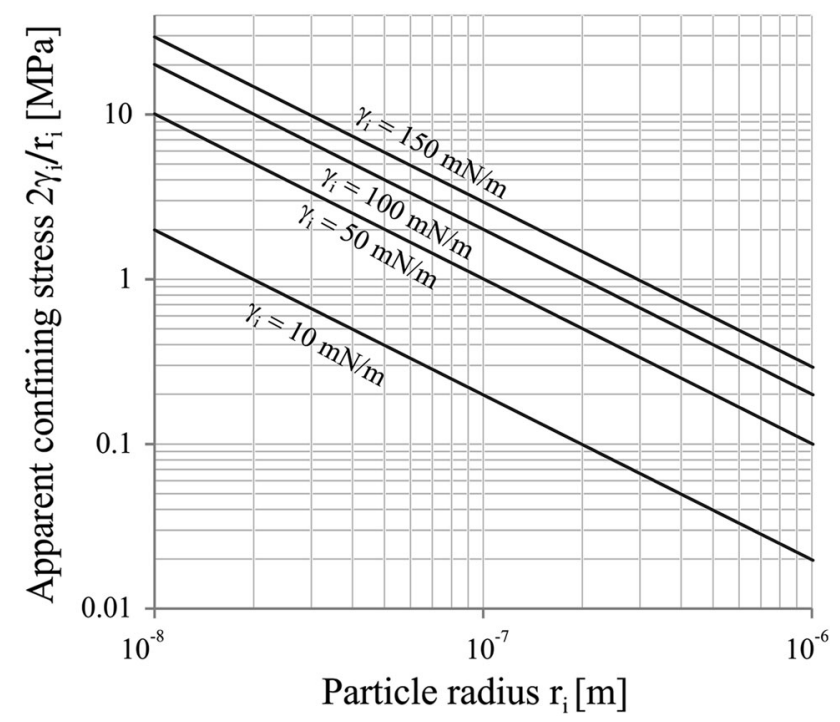

Fig. 2 Equivalent confining pressure as a function of particle radius

Table 4 Pore size data of claystones

\begin{tabular}{|c|c|c|c|c|}
\hline Reference & Rock & Method & $r_{\mathrm{p}}(\mathrm{nm})$ & Remarks \\
\hline Borst (1982) & $\begin{array}{l}\text { Pleistocene } \\
\text { claystone from a } \\
\text { depth of } 453 \mathrm{~m}\end{array}$ & $\begin{array}{l}\text { MIP }^{\mathrm{a}}, \\
\text { nitrogen } \\
\text { sorption }\end{array}$ & 50 & $\begin{array}{r}\text { Mean } \\
\text { size }\end{array}$ \\
\hline $\begin{array}{l}\text { Stroes- } \\
\text { Gascoyne } \\
\text { et al. } \\
(2007)\end{array}$ & Opalinus clay & MIP & $<20$ & Mostly \\
\hline $\begin{array}{l}\text { Desbois } \\
\text { et al. } \\
\text { (2009) }\end{array}$ & Boom clay & $\begin{array}{l}\text { Cryo- } \\
\text { SEM }^{\text {b }}\end{array}$ & $<100$ & $40 \%^{\mathrm{c}}$ \\
\hline $\begin{array}{l}\text { Muñoz et al. } \\
\text { (2009) }\end{array}$ & Opalinus clay & MIP & $\begin{array}{l}20-100 \\
10-20\end{array}$ & $\begin{array}{l}24.2 \%^{\mathrm{c}} \\
42.5 \%^{\mathrm{c}}\end{array}$ \\
\hline $\begin{array}{l}\text { Lima et al. } \\
(2010)\end{array}$ & Boom clay & MIP & 90 & Mostly \\
\hline $\begin{array}{l}\text { Lima et al. } \\
(2010)\end{array}$ & Lilla claystone & MIP & $<100$ & Mostly \\
\hline
\end{tabular}

${ }^{a}$ Mercury intrusion porosimetry

b Scanning electron microscopy

${ }^{\mathrm{c}}$ Fraction of the total porosity

\section{Solubilities}

\subsection{Gypsum}

In order to determine the equilibrium concentration under a given temperature $T$ and pressure $P_{i}$, we apply Eq. (7) with $\mathrm{d} P_{i}=\mathrm{d} T=0$, with the chemical potentials according to Eq. (11) and with the pressures as introduced in Sect. 2.1. Taking into account the stoichiometric relations $\mathrm{d}_{\mathrm{Ca}^{2+}}=$ $\mathrm{d} n_{\mathrm{SO}_{4}^{2-}}=2 \mathrm{~d} n_{\mathrm{W}}=-\mathrm{d} n_{\mathrm{G}}$ of the gypsum dissolution/precipitation reaction (Eq. (1)) as well, we obtain 
Table 5 Surface free energy data of gypsum

\begin{tabular}{ll}
\hline Reference & $\gamma_{\mathrm{G}}(\mathrm{mN} / \mathrm{m})$ \\
\hline Nielsen (1964) & 100 \\
Nielsen and Söhnel (1971) & $76-117^{\mathrm{a}}$ \\
He et al. (1994) & $12,41^{\mathrm{b}}$ \\
Lancia et al. (1999) & 37 \\
Prisciandaro et al. (2001) & 38 \\
Lancia et al. (2002) & $11-95^{\mathrm{a}}$ \\
Alimi et al. (2003) & $48,14^{\mathrm{c}}$ \\
Mahmoud et al. (2004) & 8 \\
Mishra (2012) & $27-35^{\mathrm{d}}$ \\
\hline
\end{tabular}

${ }^{a}$ Based upon literature review

${ }^{b}$ Depending on the equation used

${ }^{c}$ For heterogeneous and homogeneous nucleation, respectively

${ }^{d}$ Considering only one crystal plane

$$
\begin{aligned}
& \mathrm{d} G=\left(\mu_{\mathrm{Ca}^{2+}}+\mu_{\mathrm{SO}_{4}^{2-}}+2 \mu_{\mathrm{W}}-\mu_{\mathrm{G}}\right) \mathrm{d} n_{\mathrm{G}}= \\
& \left(\Delta_{\mathrm{r}, \mathrm{G}} G^{0}+R T \ln K_{\mathrm{G}}+p_{\mathrm{W}}\left(V_{\mathrm{G}}^{0}+\Delta_{\mathrm{r}, \mathrm{G}} V^{0}\right)\right. \\
& \left.\quad-\left(p_{\mathrm{G}}+\frac{2 \gamma_{\mathrm{G}}}{r_{\mathrm{G}}}\right) V_{\mathrm{G}}^{0}-\left(T-T_{0}\right) \Delta_{\mathrm{r}, \mathrm{G}} S^{0}\right) \mathrm{d} n_{\mathrm{G}},
\end{aligned}
$$

where $\Delta_{\mathrm{r}, \mathrm{G}} G^{0}, \Delta_{\mathrm{r}, \mathrm{G}} V^{0}, \Delta_{\mathrm{r}, \mathrm{G}} S^{0}$ and $K_{\mathrm{G}}$ are the standard Gibbs energy, the standard volume, the standard entropy and the ion activity product of gypsum dissolution, respectively:

$$
\begin{aligned}
& \Delta_{\mathrm{r}, \mathrm{G}} G^{0}=\Delta_{\mathrm{f}} G_{\mathrm{Ca}^{2+}}^{0}+\Delta_{\mathrm{f}} G_{\mathrm{SO}_{4}^{2-}}^{0}+2 \Delta_{\mathrm{f}} G_{\mathrm{W}}^{0}-\Delta_{\mathrm{f}} G_{\mathrm{G}}^{0}, \\
& \Delta_{\mathrm{r}, \mathrm{G}} V^{0}=V_{\mathrm{Ca}^{2+}}^{0}+V_{\mathrm{SO}_{4}^{2-}}^{0}+2 V_{\mathrm{W}}^{0}-V_{\mathrm{G}}^{0}, \\
& \Delta_{\mathrm{r}, \mathrm{G}} S^{0}=S_{\mathrm{Ca}^{2+}}^{0}+S_{\mathrm{SO}_{4}^{2-}}^{0}+2 S_{\mathrm{W}}^{0}-S_{\mathrm{G}}^{0}, \\
& K_{\mathrm{G}}=\frac{a_{\mathrm{Ca}^{2+}} a_{\mathrm{SO}_{4}^{2-}} a_{\mathrm{W}}^{2}}{a_{\mathrm{G}}}=\gamma_{\mathrm{Ca}^{2+}} \gamma_{\mathrm{SO}_{4}^{2-}} \frac{c_{\mathrm{Ca}^{2+}}}{c_{0}} \frac{c_{\mathrm{SO}_{4}^{2-}}}{c_{0}} a_{\mathrm{W}}^{2} .
\end{aligned}
$$

(The standard Gibbs energies of formation, molar entropies and the molar volumes appearing in these equations are given in Table 3.) At equilibrium, $\mathrm{d} G / \mathrm{d} n_{\mathrm{G}}=0$ (cf. Sect. 2.1) and, consequently, the last bracketed term in Eq. (23) is equal to zero, thus representing an equation for the determination of the equilibrium solubility product $K_{\text {eq,G }}$ as a function of the temperature $T$, the pore water pressure $p_{\mathrm{W}}$, the gypsum pressure $p_{\mathrm{G}}$ and the grain radius $r_{\mathrm{G}}$ :

$$
\begin{aligned}
R T \ln K_{\mathrm{eq}, \mathrm{G}}= & -\Delta_{\mathrm{r}, \mathrm{G}} G^{0}-p_{\mathrm{W}}\left(V_{\mathrm{G}}^{0}+\Delta_{\mathrm{r}, \mathrm{G}} V^{0}\right) \\
& +\left(p_{\mathrm{G}}+\frac{2 \gamma_{\mathrm{G}}}{r_{\mathrm{G}}}\right) V_{\mathrm{G}}^{0}+\left(T-T_{0}\right) \Delta_{\mathrm{r}, \mathrm{G}} S^{0} .
\end{aligned}
$$

Under the simplifying assumption that the calcium and sulphate ion concentrations remain equal during the chemical reaction $\left(c_{\mathrm{Ca}^{2+}}=c_{\mathrm{SO}_{4}^{2-}}=c\right)$, the equilibrium solubility product
$K_{\mathrm{eq}, \mathrm{G}}=\left(\gamma_{ \pm} \frac{c_{\mathrm{eq}, \mathrm{G}}}{c_{0}} a_{\mathrm{W}}\right)^{2}$

where $c_{\text {eq, }}$ is the equilibrium concentration of gypsum and $\gamma_{ \pm}$the mean activity coefficient of the dissolved ions:

$\gamma_{ \pm}=\sqrt{\gamma_{\mathrm{Ca}^{2+}} \gamma_{\mathrm{SO}_{4}^{2-}}}$

Equation (28) with $K_{\text {eq,G }}$ according to Eq. (29) is a nonlinear equation for the equilibrium concentration $c_{\mathrm{eq}, \mathrm{G}}$, because the mean activity coefficient $\gamma_{ \pm}$depends non-linearly on $c_{\text {eq, G}}$.

\subsection{Anhydrite}

The equilibrium concentration of anhydrite can be calculated analogously to that of gypsum (Sect. 3.1) with some minor modifications. More specifically, Eq. (28) becomes

$$
\begin{aligned}
R T \ln K_{\mathrm{eq}, \mathrm{A}}= & -\Delta_{\mathrm{r}, \mathrm{A}} G^{0}-p_{\mathrm{W}}\left(V_{\mathrm{A}}^{0}+\Delta_{\mathrm{r}, \mathrm{A}} V^{0}\right) \\
& +\left(p_{\mathrm{A}}+\frac{2 \gamma_{\mathrm{A}}}{r_{\mathrm{A}}}\right) V_{\mathrm{A}}^{0}+\left(T-T_{0}\right) \Delta_{\mathrm{r}, \mathrm{A}} S^{0},
\end{aligned}
$$

where

$\Delta_{\mathrm{r}, \mathrm{A}} G^{0}=\Delta_{\mathrm{f}} G_{\mathrm{Ca}^{2+}}^{0}+\Delta_{\mathrm{f}} G_{\mathrm{SO}_{4}^{2-}}^{0}-\Delta_{\mathrm{f}} G_{\mathrm{A}}^{0}$.

$\Delta_{\mathrm{r}, \mathrm{A}} V^{0}=V_{\mathrm{Ca}^{2+}}^{0}+V_{\mathrm{SO}_{4}^{2-}}^{0}-V_{\mathrm{A}}^{0}$,

$\Delta_{\mathrm{r}, \mathrm{A}} S^{0}=S_{\mathrm{Ca}^{2+}}^{0}+S_{\mathrm{SO}_{4}^{2-}}^{0}-S_{\mathrm{A}}^{0}$,

$K_{\mathrm{eq}, \mathrm{A}}=\left(\gamma_{ \pm} \frac{c_{\mathrm{eq}, \mathrm{A}}}{c_{0}}\right)^{2}$

and $K_{\text {eq,A }}$ and $c_{\text {eq,A }}$ denote the equilibrium solubility product and the equilibrium concentration of anhydrite.

\section{Gypsum-Anhydrite Equilibrium Relationships}

\subsection{General Case}

In order for gypsum and anhydrite to co-exist in a system, their solubilities (Eqs. (28) and (31) with $K_{\text {eq,G }}$ and $K_{\text {eq,A }}$ according to Eqs. (29) and (35), respectively) must be equal. This condition leads to the following general equilibrium condition:

$$
\begin{aligned}
& 2 R T \ln a_{\mathrm{W}}+\left(T-T_{0}\right) \Delta_{\mathrm{r}, \mathrm{GA}} S^{0} \\
& =\Delta_{\mathrm{r}, \mathrm{GA}} G^{0}+p_{\mathrm{W}}\left(V_{\mathrm{A}}^{0}-V_{\mathrm{G}}^{0}+\Delta_{\mathrm{r}, \mathrm{GA}} V^{0}\right) \\
& \quad+\left(p_{\mathrm{G}}+\frac{2 \gamma_{\mathrm{G}}}{r_{\mathrm{G}}}\right) V_{\mathrm{G}}^{0}-\left(p_{\mathrm{A}}+\frac{2 \gamma_{\mathrm{A}}}{r_{\mathrm{A}}}\right) V_{\mathrm{A}}^{0}
\end{aligned}
$$

where

$$
\Delta_{\mathrm{r}, \mathrm{GA}} G^{0}=\Delta_{\mathrm{f}} G_{\mathrm{G}}^{0}-\Delta_{\mathrm{f}} G_{\mathrm{A}}^{0}-2 \Delta_{\mathrm{f}} G_{\mathrm{W}}^{0},
$$


$\Delta_{\mathrm{r}, \mathrm{GA}} V^{0}=V_{\mathrm{G}}^{0}-V_{\mathrm{A}}^{0}-2 V_{\mathrm{W}}^{0}$

and

$\Delta_{\mathrm{r}, \mathrm{GA}} S^{0}=S_{\mathrm{G}}^{0}-S_{\mathrm{A}}^{0}-2 S_{\mathrm{W}}^{0}$

if the pore water pressure is hydrostatic, and

$$
\frac{\partial T_{\mathrm{eq}}}{\partial H}=T_{\mathrm{eq}}^{0} \rho_{\mathrm{W}} g \frac{\Delta_{\mathrm{r}, \mathrm{GA}} V^{0}}{\Delta_{\mathrm{r}, \mathrm{GA}} G^{0}+T_{0} \Delta_{\mathrm{r}, \mathrm{GA}} S^{0}}=0.00135 \frac{T_{\mathrm{eq}}^{0}}{T_{0}} \quad{ }^{\circ} \mathrm{C} / \mathrm{m},
$$

Solving Eq. (36) with respect to $T$ yields the equilibrium temperature:

$T=T_{\text {eq }}^{0}\left(1+\frac{p_{\mathrm{W}}\left(V_{\mathrm{A}}^{0}-V_{\mathrm{G}}^{0}+\Delta_{\mathrm{r}, \mathrm{GA}} V^{0}\right)+\left(p_{\mathrm{G}}+\frac{2 \gamma_{\mathrm{G}}}{r_{\mathrm{G}}}\right) V_{\mathrm{G}}^{0}-\left(p_{\mathrm{A}}+\frac{2 \gamma_{\mathrm{A}}}{r_{\mathrm{A}}}\right) V_{\mathrm{A}}^{0}}{\Delta_{\mathrm{r}, \mathrm{GA}} G^{0}+T_{0} \Delta_{\mathrm{r}, \mathrm{GA}} S^{0}}\right)$,

where $T_{\mathrm{eq}}^{0}$ denotes the equilibrium temperature under atmospheric pressure $\left(p_{\mathrm{W}}=p_{\mathrm{G}}=p_{\mathrm{A}}=0\right)$ without surface tension effects (i.e., for sufficiently large crystals):

$T_{\mathrm{eq}}^{0}=\frac{\Delta_{\mathrm{r}, \mathrm{GA}} G^{0}+T_{0} \Delta_{\mathrm{r}, \mathrm{GA}} S^{0}}{2 R \ln a_{\mathrm{W}}+\Delta_{\mathrm{r}, \mathrm{GA}} S^{0}}$.

At temperatures above the equilibrium temperature $T_{\mathrm{eq}}$, the thermodynamically stable phase is anhydrite. (Gypsum is stable, if $T<T_{\text {eq }}$.) According to Eq. (40), the equilibrium temperature depends linearly on the pressures of the constituents.

\subsection{Simplified Model for the Conditions in the Ground}

Equation (40) will be used to determine the equilibrium temperature prevailing at depth $H$ below the surface and to compare it with other theoretical predictions from the literature (Sect. 6). As in Marsal (1952) and MacDonald (1953), we assume that the solid pressure increases linearly with depth $H$ according to the lithostatic gradient (i.e., $p_{\mathrm{S}}=\rho_{\mathrm{R}} g H$, where $\rho_{\mathrm{R}}$ and $g$ denote the rock density and the gravitational acceleration, respectively). Furthermore, as in the literature, we neglect surface energy effects, which is reasonable only for sufficiently large crystals $\left(r_{\mathrm{A}}\right.$, $r_{\mathrm{G}}>1 \mu \mathrm{m}$ according to Fig. 2). Concerning the pore water pressure, we will consider the two cases investigated in the literature: it will be taken either as hydrostatic (i.e., $p_{\mathrm{W}}=\rho_{\mathrm{W}} g H$, where $\rho_{\mathrm{W}}$ is the water density) or as equal to the solid pressure $\left(p_{\mathrm{W}}=p_{\mathrm{S}}\right)$.

Equation (40) with $p_{\mathrm{A}}=p_{\mathrm{G}}=p_{\mathrm{S}}=\rho_{\mathrm{R}} \quad g \quad H, \gamma_{\mathrm{G}} /$ $r_{\mathrm{G}}=\gamma_{\mathrm{A}} / r_{\mathrm{A}}=0$ and the constants of Table 3 leads to the following expressions for the gradient of the equilibrium temperature over depth:

$$
\begin{aligned}
\frac{\partial T_{\mathrm{eq}}}{\partial H} & =T_{e q}^{0} \rho_{\mathrm{w}} g \frac{V_{\mathrm{G}}^{0}-V_{\mathrm{A}}^{0}}{\Delta_{\mathrm{r}, \mathrm{GA}} G^{0}+T_{0} \Delta_{\mathrm{r}, \mathrm{GA}} S^{0}}\left(\frac{\rho_{\mathrm{R}}}{\rho_{\mathrm{W}}}-\frac{2 V_{\mathrm{W}}^{0}}{V_{\mathrm{G}}^{0}-V_{\mathrm{A}}^{0}}\right) \\
& =-0.005 \frac{T_{\mathrm{eq}}^{0}}{T_{0}}\left(\frac{\rho_{\mathrm{R}}}{\rho_{\mathrm{W}}}-1.27\right){ }^{\circ} \mathrm{C} / \mathrm{m},
\end{aligned}
$$

if the pore water pressure is equal to the lithostatic pressure. One can readily verify that in the first case the temperature gradient is negative for the relevant values of $\rho_{\mathrm{R}} /$ $\rho_{\mathrm{W}}$, i.e. the equilibrium temperature decreases with depth.

\section{Comparison of Predicted Solubilities with Published Data}

The present Section focuses on the temperature range between 15 and $30{ }^{\circ} \mathrm{C}$, which is relevant at the depth of tunnels crossing the sulphatic claystones of the Gypsum Keuper formation (Sect. 1). Figure 3a shows the equilibrium concentration of anhydrite in pure water under atmospheric pressure $\left(p_{\mathrm{W}}=p_{\mathrm{A}}=0\right)$ as a function of the temperature according to Eq. (31). The theoretical prediction generally agrees well with the literature data. Greater deviations are observed only at low temperatures, where few data exist (those of Kontrec et al. 2002). Similarly, Fig. $3 \mathrm{~b}$ shows that the equilibrium concentration computed for gypsum (under atmospheric pressure, i.e. $p_{\mathrm{W}}=$ $p_{\mathrm{G}}=0$, and water activity $\alpha_{\mathrm{W}}=1$ ) is in good agreement with the literature data.

Blount and Dickson (1973) are among the few researchers to have studied the equilibrium concentration of anhydrite and gypsum as a function of the pore water pressure $p_{\mathrm{W}}$, albeit at rather high temperatures. For a temperature of $T=40{ }^{\circ} \mathrm{C}$ and a pressure of $p_{\mathrm{S}}=$ $p_{\mathrm{W}}=500 \mathrm{bar}$ for instance, they calculated a value of $c_{\mathrm{eq}, \mathrm{G}}=0.024 \mathrm{~mol} / \mathrm{l}$, based on their own empirical equations. A similar value of $c_{\mathrm{eq}, \mathrm{G}}=0.0278 \mathrm{~mol} / \mathrm{l}$ can be derived from the present model.

Figure 4 shows the equilibrium concentration of gypsum as a function of $\mathrm{NaCl}$-molality at $T=30{ }^{\circ} \mathrm{C}$. Most existing investigations take the molality of $\mathrm{NaCl}$ between 0 and $6 \mathrm{~mol} / \mathrm{l}$, which is a common range for saline deposits. As the NaCl-molality is relatively low in Gypsum Keuper (Sect. 2.3.4), the model verification is restricted to low 

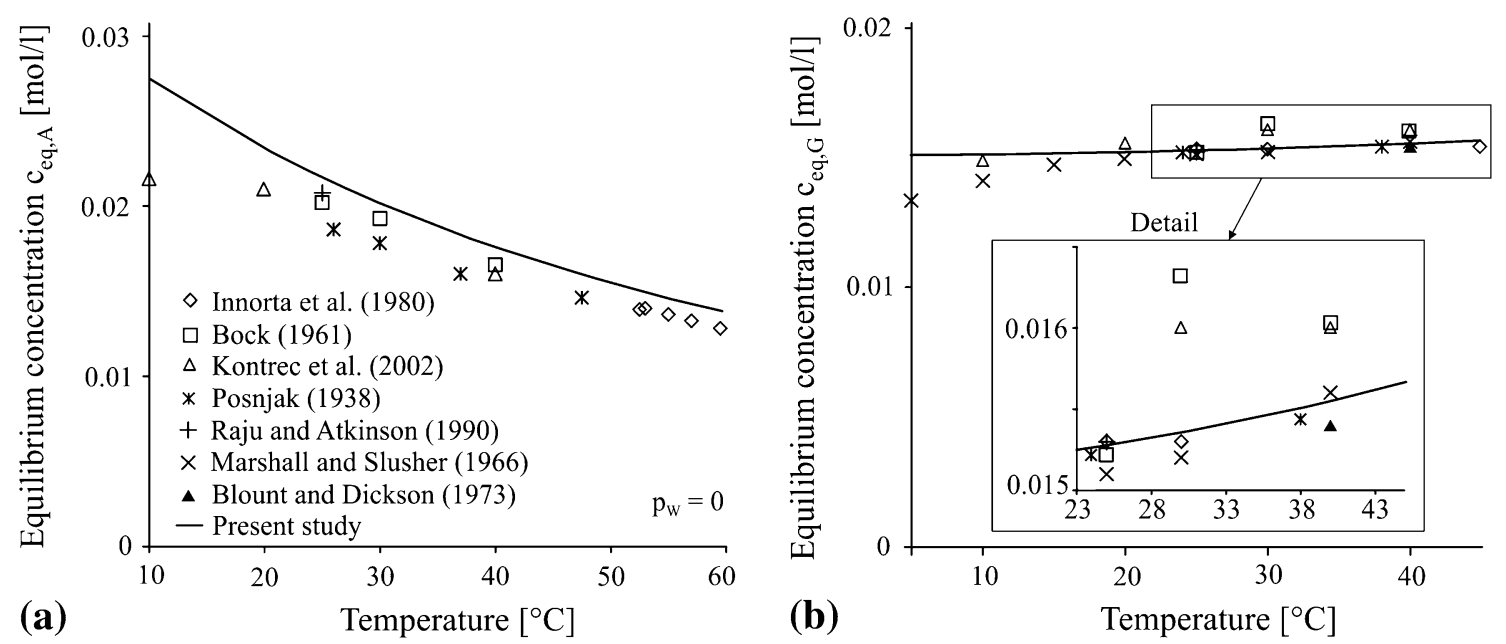

Fig. 3 a Anhydrite and $\mathbf{b}$ gypsum solubility in pure water at atmospheric pressure as a function of temperature

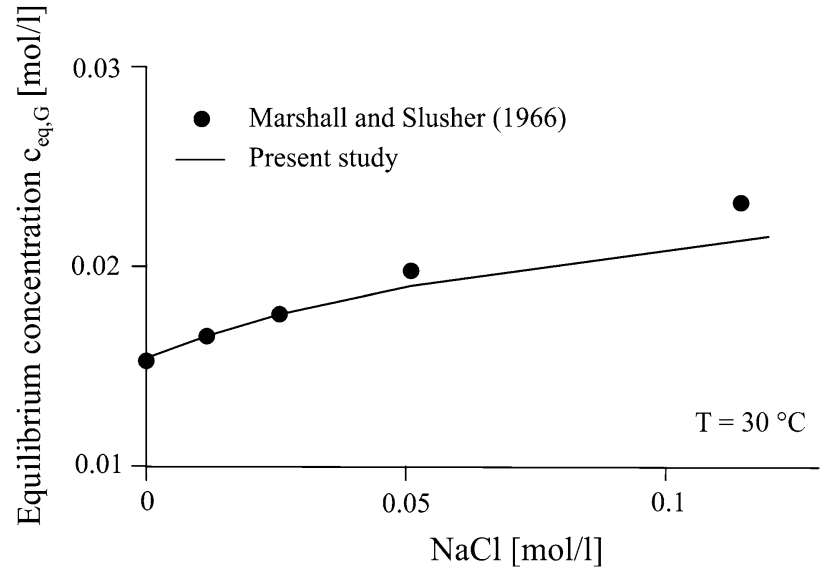

Fig. 4 Gypsum solubility at atmospheric pressure and $30^{\circ} \mathrm{C}$ as a function of NaCl-molality

$\mathrm{NaCl}$ concentrations in this case. There are experimental data at such low molalities only for gypsum (in Marshall and Slusher 1966). The predictions of Eq. (28) fit the experimental data well.

\section{Comparison Between Predicted Equilibrium Conditions and Published Data}

\subsection{Anhydrite-Gypsum Equilibrium in Pure Water}

Figure 5 shows the equilibrium temperature between anhydrite and gypsum in pure water $\left(a_{\mathrm{W}}=1\right.$, i.e. without foreign ions or interactions with clay minerals) as a function of the depth according to Sect. 4 as well as according to Marsal (1952) and MacDonald (1953). The dashed lines are based on Eq. (43), which assumes that the pore water pressure is equal to the lithostatic pressure (Marsal 1952

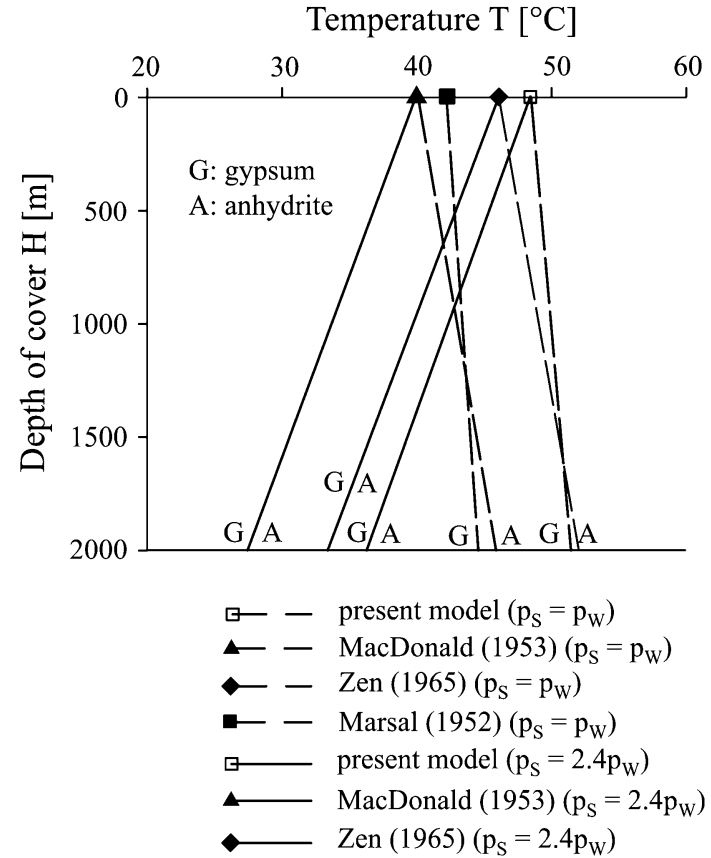

Fig. 5 Anhydrite-gypsum equilibrium temperature in pure water as a function of depth below surface

studied this case alone). The solid lines have been computed with Eq. (42), which assumes that the lithostatic pressure is higher than the pore water pressure by a factor of 2.4 (cf. MacDonald 1953).

Marsal (1952) determined the equilibrium temperature as a function of depth using a thermodynamic expression which accounts for the mineral solubilities. On the other hand, MacDonald (1953) used the empirical relationship of Kelley et al. (1941), which expresses the change in the Gibbs free energy $\Delta G$ of the anhydrite to gypsum transformation as a function of the temperature, and calculated the equilibrium temperature by setting $\Delta G$ equal to zero. 
Furthermore, he employed Eq. (7) to get the slopes of the lines in Fig. 5.

All model predictions of Fig. 5 agree well concerning the slope of the equilibrium temperature over depth line, but present differences concerning the equilibrium temperature under atmospheric pressure. According to the relationship used by MacDonald (1953), anhydrite and gypsum co-exist under atmospheric pressure at a temperature of $T=40^{\circ} \mathrm{C}$, while Marsal (1952) suggested a transition temperature of $T=42{ }^{\circ} \mathrm{C}$ using existing data of Posnjak (1938) for his model. The present model predicts a transition temperature of approximately $T=49^{\circ} \mathrm{C}$ (Eq. (41)). This value lies in the middle of the range of the transition temperatures usually found in the literature (42-60 ${ }^{\circ} \mathrm{C}$, cf. Freyer and Voigt 2003). The discrepancy between the results of MacDonald (1953) and the present model is probably due to the different values that have been used for the thermodynamic parameters (more specifically, the formation Gibbs Free Energies and the entropies, cf. Eqs. (41) and (42)). Unfortunately, MacDonald (1953) does not provide the assumed parameter values. At this point, it is worth mentioning that, according to Zen (1965), the empirical relationship used by MacDonald (1953) was not consistent, leading to erroneous results. Zen (1965) recalculated this relationship but with revised data from Kelley (1960) and found a transition temperature of $T=46^{\circ} \mathrm{C}$ at atmospheric pressure, which is closer to the value proposed in the present study (see lines marked by rhombs in Fig. 3).

\subsection{Anhydrite-Gypsum Equilibrium in $\mathrm{NaCl}$ Solutions}

MacDonald (1953) studied the gypsum-anhydrite equilibrium temperature in a $\mathrm{NaCl}$-saturated solution (under the two above-mentioned assumptions concerning the pore water pressure). In such a solution the salt concentration is approximately $6 \mathrm{~mol} / 1 \mathrm{H}_{2} \mathrm{O}$, which in turn leads to a water activity of $a_{\mathrm{W}}=0.75$ (cf. Sect. 2.3). In order to take the dissolved salt into account, MacDonald (1953) supplemented the empirical equation of Kelley et al. (1941) by a term which deals with the change in the Gibbs free energy $G$ due to the decrease in water activity. Furthermore, Hanshaw and Bredehoeft (1968) studied the equilibrium conditions in a pressure-temperature graph for $a_{\mathrm{W}}=0.93$, which corresponds to an $\mathrm{NaCl}$ concentration of $2 \mathrm{~mol} / \mathrm{l}$ $\mathrm{H}_{2} \mathrm{O}$, while assuming that $p_{\mathrm{S}}=2.3 p_{\mathrm{W}}$. As was the case with MacDonald (1953), they considered the change in the Gibbs free energy during the anhydrite-gypsum reaction, but did not provide all input parameters. Figure 6 shows the equilibrium temperature in $\mathrm{NaCl}$-solutions as a function of the depth according to the aforementioned studies (MacDonald 1953, Hanshaw and Bredehoef 1968), the relationship derived by Zen (1965) as mentioned in the previous paragraph (modified according to MacDonald

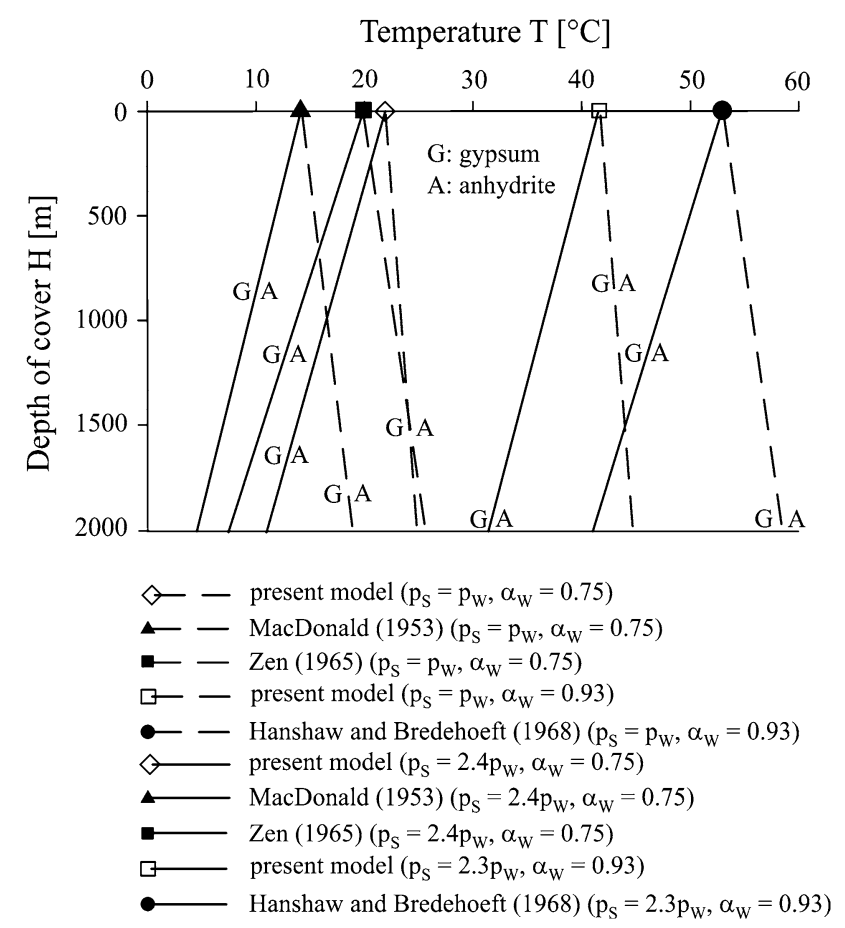

Fig. 6 Anhydrite-gypsum equilibrium temperature in $\mathrm{NaCl}$ solutions as a function of depth below surface

1953 in order to take account of the decrease in water activity) and the model of Sect. 4. Comparing the results for $a_{\mathrm{W}}=0.75$, we see that the transition temperature at atmospheric pressure is $14{ }^{\circ} \mathrm{C}$ according to MacDonald (1953), while Zen (1965) predicts a higher temperature of about $20^{\circ} \mathrm{C}$, which is much closer to the transition temperature of $22{ }^{\circ} \mathrm{C}$ predicted by Eq. (41).

The influence of water activity on the equilibrium between anhydrite and gypsum has been investigated both theoretically (Freyer and Voigt 2003; MacDonald 1953; Raju and Atkinson 1990; Marshall and Slusher 1966; Møller 1988) and experimentally (Hardie 1967; Bock 1961; Blount and Dickson 1973) in terms of $\mathrm{NaCl}$ concentration. Figure 7 shows the gypsum-anhydrite equilibrium temperature as a function of the water activity according to the literature and to the model of Sect. 4 . Again, a satisfactory agreement can be observed.

\section{General Equilibrium Diagram}

The present Section makes a synthesis of the results of the previous Sections, illustrating in a single diagram the effect of the several parameters which influence the equilibrium between anhydrite and gypsum. According to Eq. (36), the latter is a function of the temperature $T$, the pore water pressure $p_{\mathrm{W}}$, the water activity $\alpha_{\mathrm{W}}$ (which according to Sects. 2.3.2 and 2.3.3 takes account of the effects of the clay 


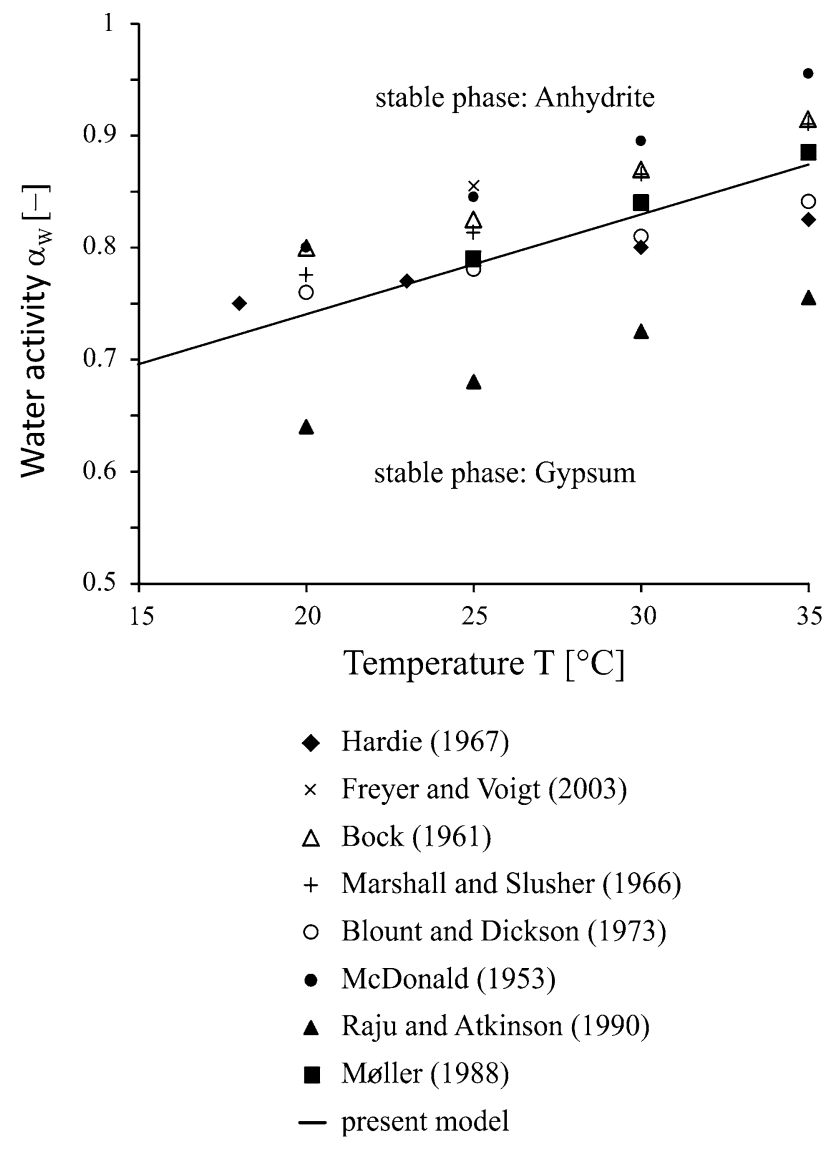

Fig. 7 Relationship between temperature and water activity at anhydrite-gypsum equilibrium

minerals and of foreign ions in the pore solution), the gypsum and anhydrite pressures $p_{\mathrm{G}}$ and $p_{\mathrm{A}}$ (Sect. 2.1) and the particle radii $r_{\mathrm{G}}$ and $r_{\mathrm{A}}$ (due to surface energy effects, Sect. 2.4). Under certain simplifying assumptions, the interaction among these parameters can be visualised by means of one single equilibrium diagram (Fig. 8). The assumptions are as follows: the pressures of the anhydrite and gypsum are equal, i.e. $p_{\mathrm{G}}=p_{\mathrm{A}}=p_{\mathrm{s}}$; the solid-liquid interfacial effects are negligible for the anhydrite; and the radius of the gypsum particles $r_{\mathrm{G}}$ corresponds to the pore radius $r_{\mathrm{p}}$ (cf. Section 2.4). Figure 8 shows the anhydrite-gypsum equilibrium diagram for the two boundaries of the relevant temperature range $\left(T=15\right.$ and $30^{\circ} \mathrm{C}$, see Sect. 1$)$, for different values of the water activity $a_{\mathrm{W}}$ and for two assumptions concerning the pore water pressure: atmospheric pressure $\left(p_{\mathrm{W}}=0\right)$ as well as a pore water pressure of $p_{\mathrm{W}}=3 \mathrm{MPa}$, which corresponds to a depth of cover of $300 \mathrm{~m}$. The diagram has been calculated assuming a value of $\gamma_{\mathrm{G}}=80 \mathrm{mN} / \mathrm{m}$.

The stable phase above and below each curve is gypsum and anhydrite, respectively. According to Fig. 8, the pore water pressure has a negligible effect on the equilibrium condition for the depths concerned. The effect of the other parameters is, however, significant. A high water activity

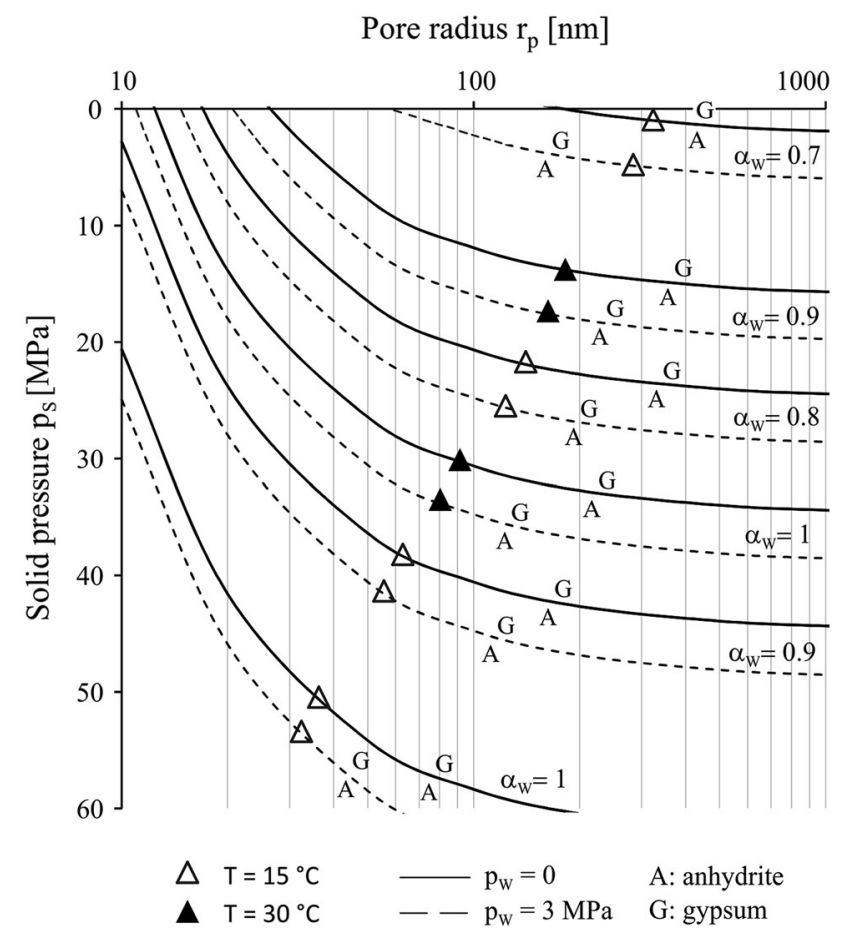

Fig. 8 Anhydrite-gypsum equilibrium condition in terms of pore radius and solid pressure at different temperatures, water activities and pore water pressures

$a_{\mathrm{W}}$, a low solid pressure $p_{\mathrm{s}}$, a low temperature $T$ and a big pore radius $r_{\mathrm{p}}$ favour gypsum as the stable phase.

\section{Conclusions}

A rigorous thermodynamic model has been presented for determining the equilibrium conditions between anhydrite, gypsum and water. The model predictions are close to the measured solubilities reported in the literature and agree with older theoretical predictions with respect to the gradient of the equilibrium temperature over depth. The discrepancies among older theoretical estimations of the equilibrium temperature under atmospheric pressure can be attributed to the different thermodynamic data used.

In addition to the parameters usually considered (solid and fluid pressure, temperature, concentration of foreign ions), we discussed and incorporated into our model the effects of pore size and of clay minerals. These two factors are important particularly in the case of claystones with very small pores (smaller than $1 \mu \mathrm{m}$ ) and finely distributed anhydrite. Small crystals have a higher chemical potential than big crystals. Clay minerals lower the chemical potential of water. Consequently, both factors-a small pore size and the presence of clay minerals-increase the solubility of gypsum, thus shifting the thermodynamic equilibrium in favour of anhydrite. 
Furthermore, in contrast to earlier research, the anhydrite-gypsum equilibrium has been approached starting from the underlying dissolution and precipitation equations. More specifically, account was taken of the anhydrite-water and gypsum-water equilibria; equations were derived for the gypsum and anhydrite solubilities; and these equations were applied to the special case of the anhydrite-gypsum equilibrium. (It is a special case, because at anhydritegypsum equilibrium both minerals exhibit the same solubility.) The results of the paper are thus also valuable for future research into the coupled processes in anhydritic claystones, where sulphate dissolution and/or precipitation generally occur simultaneously with diffusive and advective transport of the dissolved ions.

Acknowledgments This paper evolved within the framework of the research project 'Modelling of anhydritic swelling claystones' which is being carried out at the ETH Zurich, financed by the Swiss National Science Foundation (SNF) with Project Nr. 200021-126717/1 and the Swiss Federal Roads Office (FEDRO) with Project Nr. FGU 2010-007. The Authors would like to acknowledge Prof. Dr. Robert Flatt, ETH Zurich, for his valuable suggestions concerning the importance of pore size and liquid-crystal interfacial effects.

\section{References}

Alimi F, Elfil H, Gadri A (2003) Kinetics of the precipitation of calcium sulfate dihydrate in a desalination unit. Desalination 157:9-16

Amstad C, Kovári K (2001) Untertagbau in quellfähigem Fels. Schlussbericht Forschungsauftrag 52/94 des Bundesamts für Strassen ASTRA

Anagnostou G, Pimentel E, Serafeimidis K (2010) Swelling of sulphatic claystones-some fundamental questions and their practical relevance. Geomech Tunn 3(5):567-572

Anderson GM (1996) Thermodynamics of Natural systems. University of Toronto, Wiley

Atkins P, De Paula J (2006) Atkins' physical chemistry, 8th edn. Oxford University Press, Oxford

Bachema (1995-7) Chemische Untersuchung von Wasserproben Adlertunnel Bahn 2000. Several reports by "Institut Bachema AG, Analytische Laboratorien"

Beck D, Thullner T (1998) Der Engelbergbasistunnel und der Umbau des Autobahndreiecks Leonberg. Tiefbau, Heft 10:692-699

Berdugo IR (2007) Tunnelling in sulphatic-bearing rocks-expansive phenomena. Doctoral Thesis, Universitat Politècnica de Catalunya

Bihannic I, Delville A, Demé B, Plazanet M, Villiéras F, Michot JL (2009) Clay swelling: new insights from neutron-based techniques. Neutron Scattering Applications and Techniques, Part III, 521-546

Blandamer MJ, Engberts JBFN, Gleeson PT, Reis JOCR (2005) Activity of water in aqueous systems; A frequently neglected property. Chem Soc Rev 34:440-458

Blount CW, Dickson FW (1973) Gypsum-anhydrite equilibria in systems $\mathrm{CaSO}_{4}-\mathrm{H}_{2} \mathrm{O}$ and $\mathrm{CaCO}_{3}-\mathrm{NaCl}-\mathrm{H}_{2} \mathrm{O}$. Am Mineral 58:323-331

Bock E (1961) On the solubility of anhydrous calcium sulfate and of gypsum in concentrated solutions of sodium chloride at $25^{\circ} \mathrm{C}$, $30{ }^{\circ} \mathrm{C}, 40{ }^{\circ} \mathrm{C}$ and $50{ }^{\circ} \mathrm{C}$. Can J Chem 39:1746-1751
Borst LR (1982) Some effects of compaction and geological time on the pore parameters of argillaceous rocks. Sedimentology 29:291-298

Butscher C, Huggenberger P, Zechner E, Einstein HH (2011) Relation between hydrogeological setting and swelling potential of claysulphate. Eng Geol 122:204-214

Chenevert ME (1969) Adsorptive pore pressure of argillaceous rocks. In: Proceeding of II Symposium on Rock Mechanics, University of California, Berkeley, pp 599-627

Dahlen FA (1992) Metamorphism of nonhydrostatically stressed rocks. Am J Sci 292:184-198

Davies CW (1962) Ion association. Butterwoths, London

Debye P, Hückel E (1923) Zur Theorie der Elektrolyte. Phys Z 24:185-206

Derjaguin BV, Churaev VN, Muller MV (1987) Surface forces. Consultants Bureau, New York

Desbois G, Urai LJ, Kukla AP (2009) Morphology of the pore space in claystones-evidence from BIB/FIB ion beam sectioning and cryo-SEM observations. Electronic-earth 4:15-22

Dewers T, Ortoleva JP (1989) Mechano-chemical coupling in stressed rocks. Geochim Cosmochim Acta 53:1243-1258

Dormieux L, Lemarchand E, Coussy O (2003) Macroscopic and micromechanical approaches to the modelling of osmotic swelling in clays. Transp Porous Media 50:75-91

Einstein HH (2000) Tunnels in Opalinus clayshale-a review of case histories and new developments. Tunn Undergr Space Technol 15(1):13-29

Fermi E (1936) Thermodynamics. Dover Publications, Inc., New York

Flatt JR, Scherer WG (2008) Thermodynamics of crystallization stresses in DEF. Cem Concr Res 38:325-336

Freundlich H (1922) Colloid and Capillary Chemistry. Translated by Hatfield HS, Dutton EP. Company Publishers, New York, p 883

Freyer D, Voigt W (2003) Crystallization and phase stability of $\mathrm{CaSO}_{4}$ of and $\mathrm{CaSO}_{4}$ - based salts. Monatsh Chem 134:693-719

Gildseth W, Habenschuss A, Spedding FH (1972) Precision measurements of densities and thermal dilation of water between $5^{\circ}$ and $80{ }^{\circ} \mathrm{C}$. J Chem Eng Data 17(4):402-409

Gimmi T, Waber HN (2004) Modelling of tracer profiles in pore water of argillaceous rocks in the Benken Borehole: stable water isotopes, chloride, and chlorine isotopes. NAGRA technical report 04-05

Grob H (1972) Schwelldruck im Belchentunnel. Internationales Symposium für Untertagbau, Luzern, pp 99-119

Hanshaw BB, Bredehoeft JD (1968) On the maintenance of anomalous fluid pressures: II. Source layer at depth. Geol Soc Am Bulletin 79:1107-1122

Hardie LA (1967) The gypsum-anhydrite equilibrium at one atmosphere. Amer Mineral 52:171-200

Hauber L (1991) Geologie des Bözbergtunnels. N3: Bözberg- und Habsburgtunnel. Mitteilungen der Schweizerischen Gesellschaft für Boden- und Felsmechanik, Heft 123

He S, Oddo EJ, Thomson BM (1994) The nucleation kinetics of calcium sulfate dihydrate in $\mathrm{NaCl}$ solutions up to $6 \mathrm{~m}$ and $90{ }^{\circ} \mathrm{C}$. J Colloid Interface Sci 162:297-303

Huggenberger P (2012) University of Basle, personal communication

Innorta G, Rabbi E, Tomadin L (1980) The gypsum-anhydrite equilibrium by solubility measurements. Geochim Cosmochim Acta 44:1931-1936

Kelley KK (1960) Contributions to the data on theoretical metallurgy, XIII. High-temperature heat-content, heat-capacity, and entropy data for the elements and inorganic compounds. US Bur Mines Bull 584:232

Kelley KK, Southard JC, Anderson CT (1941) Thermodynamic properties of gypsum and its dehydration products. US Bur Mines Tech Paper 625 
Kirschke D, Kuhnhenn K, Prommersberger G (1991) Der Freudensteintunnel: Eine Herausforderung für den planenden Ingenieur. Ingenieurbauwerke, DB Neubaustrecke Mannheim-Stuttgart 8:5-39

Kontrec J, Kralj D, Brečević L (2002) Transformation of anhydrous calcium sulphate into calcium sulphate dihydrate in aqueous solutions. J Cryst Growth 240:203-211

Kurz G, Spang J (1984) Instandsetzung und Erneuerung der Blähstrecke des Kappelesbergtunnels, Bautechnik, Heft 11:365-376

Lancia A, Musmarra D, Prisciandaro M (1999) Measuring induction period for calcium sulfate dihydrate precipitation. AIChE J 45(2):390-397

Lancia A, Musmarra D, Prisciandaro M (2002) Calcium sulfate. Contribution on Kirk-Othmer Encyclopedia of chemical technology, 4th edn. Wiley, New York

Lima A, Pineda AJ, Romero E (2010) Thermal pulse effects on the stiffness degradation of unsaturated clayey materials. In: Proceeding of international conference on unsaturated soils. 'Unsaturated soils'. Taylor \& Francis, Barcelona, pp 567-572

Lothenbach B (2012) EMPA Zurich, personal communication

Low PF, Margheim FJ (1979) The swelling of clay. I. Basic concepts and empirical equations. Soil Sci Soc Am J 43:473-481

LPM (2000-6) Wasseranalysen Chienberg Tunnel. Several reports by "Labor für Prüfung und Materialtechnologie"

MacDonald GJF (1953) Anhydrite-gypsum equilibrium relations. Am J Sci 251:884-898

Madsen FT, Müller-Vonmoos M (1988) Das Quellverhalten der Tone. Mitteil. des Inst. für Grundbau und Bodenmechanik $\mathrm{Nr}$. 133:39-50

Mahmoud MHH, Rashad MM, Ibrahim IA, AbdelAal EA (2004) Crystal modification of calcium sulfate dihydrate in the presence of some surface-active agents. J Colloid Interface Sci 270:99-105

Marsal D (1952) Der Einfluss des Druckes auf das System $\mathrm{CaSO}_{4}-$ $\mathrm{H}_{2} \mathrm{O}$. Heidelberger Beiträge zur Mineralogie and Petrographie 3:289-296

Marshall WL, Slusher R (1966) Thermodynamics of calcium sulphate dihydrate in aqueous sodium chloride solutions, $0-110^{\circ} \mathrm{C}$. J Phys Chem 70:4015-4027

Medici F, Rybach L (1995) Geothermal map of Switzerland 1995 (heat flow density), Matériaux pour la Géologie de la Suisse, Geophysique Nr., p 30

Mering J (1946) On the hydration of montmorillonite. Trans Faraday Soc 42B:205-219

Merkel JB, Planer-Friedrich B (2008) Groundwater geochemistry, 2nd edn. Springer, Berlin

Meyer M (2001) Die Geologie des Adlertunnels. Bull Angew Geol 6(2):199-208

Millero FJ (1972) The partial molar volume of electrolytes in aqueous solutions. Water and Aqueous Solution, Wiley

Mishra RK (2012) Simulation of interfaces in construction materials: tricalcium silicate, gypsum, and organic modifiers. Phd Thesis, University of Akron

Mitchell JK, Soga K (2005) Fundamentals of Soil Behavior, 3rd edn. Wiley, New York

Møller N (1988) The prediction of mineral solubilities in natural waters: a chemical equilibrium model for the $\mathrm{Na}-\mathrm{K}-\mathrm{Ca}-\mathrm{Cl}-$ $\mathrm{SO}_{4}-\mathrm{H}_{2} \mathrm{O}$ system to high temperature and concentration. Geochim Cosmochim Acta 52:821-837

Muñoz JJ, Alonso EE, Lloret A (2009) Thermo-hydraulic characterization of soft rock by means of heating pulse test. Géotechnique 59(4):293-306

Nielsen EA (1964) Kinetics of precipitation. Pergamon Press, Oxford

Nielsen EA, Söhnel O (1971) Interfacial tensions electrolyte crystalaqueous solution, from nucleation data. $\mathrm{J}$ Cryst Growth $11: 233-242$
Noher H-P, Meyer N (2002) Belchentunnel Versuchsdrainagestollen, Beurteilung der Wasseranalysen. Report 1510720.003 by Geotechnisches Institut AG

Nordstrom DK, Plummer LN, Langmuir D, Busenberg E, May HM, Jones BF, Parkhurst DL (1990) Revised chemical equilibrium data for major water-mineral reactions and their limitations. In: Melchior D et al (eds) Chemical modeling of aqueous systems II, pp 398-413

Passioura BJ (1980) The meaning of matric potential. J Exp Bot 31(123):1161-1169

Paul A, Wichter L (1996) Das Langzeitverhalten von Tunnelbauwerken im quellenden Gebirge-Neuere Messergebnisse vom Stuttgarter Wagenburgtunnel, Taschenbuch für den Tunnelbau, Verlag Glückauf, Essen

Pearson FJ, Arcos D, Bath A, Boisson J-Y, Fernández AM, Gäbler H-E, Gaucher E, Gautschi A, Griffault L, Hernán P, Waber HN (2003) Mont Terri Project-Geochemistry of water in the Opalinus clay formation at the Mont Terri Rock Laboratory. Reports of the FOWG, Geology Series, No. 5-Bern

Philip RJ (1977) Unitary approach to capillary condensation and adsorption. J Chem Phys 66(11):5069-5075

Pitzer KS (1973) Thermodynamics of electrolytes. I Theoretical basis and general equations. J Phys Chem 77:268-277

Posnjak E (1938) The system $\mathrm{CaSO}_{4}$. Am J Sci (5th edn) 35-A: 247-272

Prisciandaro M, Lancia A, Musmarra D (2001) Gypsum nucleation into sodium chloride solutions. AIChE J 47(4):929-934

Raju K, Atkinson G (1990) Thermodynamics of 'scale' mineral solubilities. 3. Calcium sulfate in aqueous $\mathrm{NaCl}$. J Chem Engin Data 35:361-367

Rolnick LS (1954) The stability of gypsum and anhydrite in the geologic environment. PhD thesis, MIT

Scanlon RB, Andraski JB, Bilskie J (2002) Miscellaneous methods for measuring of water potential. Methods of soil analysis, Part 4, Physical methods. Soil Science Society of America, Madison, pp 643-670

Schaectherle K (1929) Die Dichtung und Entwässerung des Schanztunnels bei Fichtenberg, Die Bautechnik, Heft, p 40

Schaeren G, Norbert J (1989) Tunnel du Mont Terri et du Mont Russelin-La traversée des 'roches à risques': marnes et marnes à anhydrite. Juradurchquerungen-aktuelle Tunnelprojekte im Jura Mitteilungen der Schweizerischen Gesellschaft für Bodenund Felsmechanik, Heft, p 119

Scherer WG (1999) Crystallization in pores. Cem Concr Res 29:1347-1358

Serafeimidis K, Anagnostou G (2012) On the solubilities of anhydrite and gypsum. In: Proceeding of second international symposium on constitutive modeling of geomaterials, advances and new applications. Beijing

Serafeimidis K, Anagnostou G (2012) On the kinetics of the chemical reactions underlying the swelling of anhydritic rocks. Eurock 2012, Stockholm

Serafeimidis K, Anagnostou G (2013) On the time-development of sulphate hydration in anhydritic swelling rocks. Rock Mech Rock Eng 46:619-634

Steiger M (2005a) Crystal growth in porous materials-I: the crystallization pressure of large crystals. J Cryst Growth 282:455-469

Steiger M (2005b) Crystal growth in porous materials-II: influence of crystal size on the crystallization pressure. J Cryst Growth 282:470-481

Stroes-Gascoyne S, Schippers A, Schwyn B, Poulain S, Segreant C, Simonoff M, Le Marrec C, Altmann S, Nagaoka T, Mauclaire L, McKenzie J, Daumas S, Vinsot A, Beaucaire C, Matray MJ (2007) Microbial community analysis of Opalinus clay drill core 
samples from the Mont Terri underground research laboratory, Switzerland. Geomicrobiol J 24(1):1-17

Toriumi T, Hara R (1938) On the transition point of calcium sulphate in water and concentrated seawater. Tech Rep Tohoku Imp Univ 12:572-590

Tuller M, Or D, Dudley ML (1999) Adsorption and capillary condensation in porous media: liquid retention and interfacial configuration in angular pores. Water Resour Res 35(7):1949-1964

Van Loon LR, Soler JM (2003) Diffusion of HTO, ${ }^{36} \mathrm{Cl}^{-},{ }^{125} \mathrm{I}^{-}$and ${ }^{22} \mathrm{Na}^{+}$in Opalinus clay: effect of confining pressure, sample orientation, sample depth and temperature. NAGRA Technical Report 03-07

Van't Hoff JH, Armstrong EF, Hinrichsen W, Wigert F, Just G (1903) Gips und Anhydrite. Zeitschrift f. physik. Chemie 45:257-306

Voegelin A, Kretzschmar R (2002) Stability and mobility of colloids in Opalinus clay. NAGRA Technical Report 02-14
Washburn EW (1926-1933) International critical tables of numerical data, physics, chemistry and technology. New York, Published for the National Research Council by McGraw-Hill

Wegmüller MC (2001) Einflüsse des Bergwassers auf Tiefbau/ Tunnelbau

White WM (2005) Geochemistry. John-Hopkins University Press

Yong NR (1999) Soil suction and soil-water potentials in swelling clays in engineered clay barriers. Eng Geol 54:3-13

Yong NR, Warkentin BP (1975) Soil properties and behaviour. Elsevier, Amsterdam

Zehringer M (1997) Wasseranalysen Brunnenbohrungen Tal Pratteln Adlertunnel. Several reports by "Gewässerschutzamt Kanton Basel-Stadt, Abteilung Labor"

Zen E-An (1965) Solubility measurements in the system $\mathrm{CaSO}_{4-}$ $\mathrm{NaCl}-\mathrm{H}_{2} \mathrm{O}$ at $35^{\circ}, 50^{\circ}$ and $70^{\circ} \mathrm{C}$ and one atmosphere pressure. J Petrol 6 Part 1:124-164 